NBSIR 81-2396 (ONR)

\title{
Passive Films, Surface Structure and Stress Corrosion and Crevice Corrosion Susceptibility
}

U.S. DEPARTMENT OF COMMERCE

National Bureau of Standards

Chemical Stability and Corrosion Division and

Surface Science Division

Washington, DC 20234

August 1981

Technical Summary Report No. 11

Issued November 1981

Prepared for

nffice of Naval Research

QC partment of the Navy

100 lington, VA 22217 
PASSIVE FILMS, SURFACE STRUCTURE AND STRESS CORROSION AND CREVICE CORROSION SUSCEPTIBILITY

J. Kruger, J. J. Ritter, J. J. Carroll, and A. J. Melmed

U.S. DEPARTMENT OF COMMERCE

National Bureau of Standards

Chemical Stability and Corrosion Division and

Surface Science Division

Washington, DC 20234

\section{August 1981}

DISTRIBUTION OF THIS DOCUMENT IS UNLIMITED

Issued November 1981

\section{Prepared for}

Office of Naval Research

Department of the Navy

Arlington, VA 22217

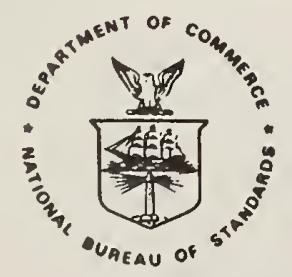

U.S. DEPARTMENT OF COMMERCE, Malcolm Baldrige, Secretary NATIONAL BUREAU OF STANDARDS, Ernest Ambler, Director 


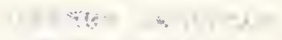

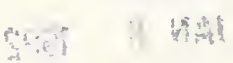


[Part I -

From "Proceedings of the International

Conference on Corrosion Control by

Organic Coatings," Henry Leidheiser, Jr., ed., NACE, Houston, TX (1981) and from SP-485, Society of Automotive Engineers, Warrendale, PA (1981).]

\title{
Studies on the Sub-Coating
} Enviroment of Coated Iron Using Qualitative Ellipsometric and Electrochemical Techniques

\author{
J. J. Ritter and J. Kruger \\ Chemical Stability and Corrosion Div. \\ National Bureau of Standards
}

\section{ABSTRACT}

Transparent organic coatings on iron are used to simulate painted metal surfaces for simultaneous ellipsometric and electrochemical measurements. These studies show that significant changes occur both in the metal oxide film and in the sub-coating environment during prolonged immersion in dilute $\mathrm{Cl}^{-}$media. The relationship of these changes to phenomena such as metal passivation, coating delamination, and inhibitor behavior are addressed.

THE BEHAVIOR OF ORGANIC COATINGS on metals has been examined with a variety of electrical and electrochemical measurement techniques including dc resistance, ac resistance, capacitance, corrosion potential etc. (1)*. The objectives of these studies has been both to evaluate coating efficacy and to probe the processes which lead to coating fallure. We describe in this work results from the application of a new technique of combined ellipsometric and electrochemical measurements to a study of the fundamental corrosion processes on metals protected with organic coatings.

The detalls of the technique have been described previously (2). Briefly, painted metal is simulated using a polished iron specimen coated with transparent cellulose nitrate (collodion). The specimen is provided with a miniature probe to measure $\mathrm{pH}$ under the coating while visible, elliptically polarized light passes through the coating and is reflected from the metal surface. Computer modeling and experiments with collodion on relatively inert gold surfaces have indicated that for the ellipsometric conditions chosen $\left(\lambda=546.1 \mathrm{~nm}, \Phi=68^{\circ}\right)$ the ellipsometric parameters $\Delta$ and $\psi$ are most sensitive to changes at the metal-metal oxide surface. Thus, for example, variations in the ellipsomet-ric parameter $\Delta$ can be related to the growth or dissolution of the oxide film at the surface of the metal and under the organic coating. At the same time, the $\mathrm{pH}$ of the environment to which ^Numbers in parentheses designate References at end the metal is subjected can be assessed.

The technique has been used to study both coated iron and iron with various inhibitors available efther in or under the coating material. Due to the complexity of the multilayered system which must be dealt with in these experiments, the ellipsometric results are useful only in a qualitative sense. However, cathodic reduction experiments done on stripped iron specimens in deaerated borate buffer environments permitted some semi-quantitative assessment of sub-coating events.

\section{EXPERTMENTAL}

Specimen preparation details have been published previously (2). For the present purposes it suffices to say that the iron specimens were cast in epoxy, polished to a $0.05 \mu \mathrm{m}$ finish and dipped in a $1: 1$ collodion-methanol mixture to give a coating of from $10-30 \mathrm{um}$ in thickness over the face of both the metal and the epoxy mount. The prepared specimen was inserted in an improved mount (see Fig. 1) and set in a polytetrafluoroethlene lined cell which was filled with $0.05 \mathrm{~N} \mathrm{NaCl}$. Inhibitor materials were either applied directly to the metal before coating or dispersed as a finely ground powder in the collodion-methanol mixture. For the case of $\mathrm{SrCrO}_{4}$, the metal specimen was dip coated, finely powdered $\mathrm{SrCrO}_{4}$ applied to the surface of the semi-cured coating and a second coat applied to cover the inhibitor.

The phosphate-chromate surface treatment was accomplished as follows: Solution $\mathrm{I}: \mathrm{H}_{3} \mathrm{PO}_{4} 3.0 \mathrm{~g}$, $\mathrm{ZnO} 1.5 \mathrm{~g}, \mathrm{NaNO}_{3} 1.0 \mathrm{~g}$, make up with $\mathrm{H}_{2} \mathrm{O}$ to $100 \mathrm{ml}$. Solution II : $\mathrm{K}_{2} \mathrm{Cr}_{2} \mathrm{O}_{7} 0.7 \mathrm{~g}, \mathrm{H}_{3} \mathrm{PO}_{4} 0.5 \mathrm{~g}$, make up with $\mathrm{H}_{2} \mathrm{O}$ to $100 \mathrm{ml}$.

The solutions were used at room temperature. The face of the specimen was rotated in a horizontal plane at $50 \mathrm{rpm}$ in a mixture comprised of 8 $\mathrm{ml}$ of solution $\mathrm{I}$ and $2 \mathrm{ml}$ of solution II for a period of six minutes. This procedure gave an homogeneous surface finish which retained sufficient specular quality to allow ellipsometric measurements.

The ellipsometric measurements on coated iron specimens show changes in both the $\Delta$ and 


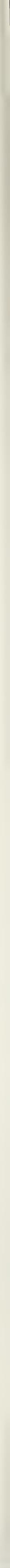


$\psi$ parameters with time (see Figs, 2 and 3 ). By far, the largest change is seen in the $\Delta$ parameter which always shows a decrease. It is known that several factors could contribute to this directional change in $\Delta$, among them, metal oxide film growth, surface roughening (3) and possibly coating deterioration. These effects and their relative contributions to the systems under study were investigated as described below.

The extent of oxide film growth under the coi ings was estimated at the conclusion of an experiment by stripping the coating with methanol, and cathodically reducing the metal surface at $-1000 \mathrm{mV}$ S.C.E. in deaerated borate buffer solutions ( $\mathrm{pH} 8.5$ ) while observing the surface with the ellipsometer. Oxide film thicknesses were alculated assuming that the film was essentially $\mathrm{Fe}_{2} \mathrm{O}_{3}$ and that each degree change in $\Delta$ corresponded to $0.6 \mathrm{~nm}$ of $\mathrm{film}$.

The presence of surface roughness was qualitatively detected by cycling the specimen potential between -1000 and $+200 \mathrm{mV}$ approximately 60 times. A significant increase in the $\Delta$ parameter indicated surface smoothing as a result of electrochemical polishing.

Contributions from the coating to changes in $\triangle$ were estimated by ellipsometrically monitoring collodion coated gold specimens in $0.05 \mathrm{~N} \mathrm{NaCl}$ and in saturated $\mathrm{NaOH}(\mathrm{pH} \sim 15)$.

\section{RESULTS AND DISCUSSION}

The examples of experimental results shown in Figs. 2 and 3 indicate at least two stages of activity. In the first stage, (generally up to $21000 \mathrm{~min}$ ) the $\mathrm{pH}$ tends to rise gradually while the ellipsometric parameter $\Delta$ tends to increase several degrees*. As the $\mathrm{pH}$ approaches 11 , the $A$ values undergo a significant decrease which signifies the beginning of the second stage. Invariably, small anodic regions become visible during the second stage with final overall anodic to cathodic area ratios ranging from $1 / 30$ to $1 / 600$.

In some experiments, particularly in those ere no inhibitor is present and the $\mathrm{pH}$ remains high, a third stage is observed where $\Delta$ fluctuates. This behavior can be seen in Fig. 2 .

The most significant change occurs in the $\Delta$ parameter during the second stage. In cases where no inhibitor is present this change arises from three factors given below along with their estimated contributions to the overall $\delta \Delta$ : (1) metal surface roughening, $\sim 55$ percent; (2) oxide film growth, 235 percent, and ( 3 ) changes in coating material in a high $\mathrm{pH}$ environment $\sim 10$ percent. It will be noted that the second stage changes of $\Delta$ with time appear to approximate a semi logarithmic relationship, i.e., $d \Delta=$ $k \log t+c$. This law is frequently observed in the growth of passive films on metals (4). The rate constants, $k$, for coated iron with various applications of inhibitors are summarized in Table 1.

*In some experiments, the $\Delta$ values tend to decrease several degrees over the first stage. The contributing factors to this portion of the curve are not fully known.
With reference to Table 1 it is readily seen that the rate of ellipsometrically observed subcoating events for coated iron and for coated iron which had been given a phosphate-chromate pretreatment are quite comparable. However, when $\mathrm{K}_{2} \mathrm{CrO}_{4}$ is present at the metal surface, the rate is slower by a factor of 10 , whereas $\mathrm{ZnCrO}_{4}$ applied in a similar fashion slows the rate by only a factor of two. This phenomenon may be partly related to solubility differences between the two inhibitors. Inhibitors dispersed throughout the coating give a similar factor of two reduction in the rate. The mechanism by which chromates inhibit corrosion reportedly involves the incorporation of chromium into an existing oxide film, i.e. a chemical and structural modification of the existing oxide film which results in improved protection (5). The rate constants derived from the present work seem to be related to inhibitor ion mobilities and accessibilities to the substrate surface. Contributions to the $\Delta$ parameter due to modifications of the metal oxide (e.g. upon the incorporation of chromium) which may change its refractive index, are expected to

\section{TABLE I}

Stage II Rate Constants for Ellipsometrically Measured Sub-coating Events on Collodion-Coated Iron in $0.05 \mathrm{~N} \mathrm{NaC1}$

Summary of Ellipsometric Rate Constants for Stage II Events

Semi-Logarithmic Behavior Assumed $\mathrm{d} \Delta=\mathrm{k} \log \mathrm{t}+\mathrm{c}$

\begin{tabular}{lcc}
$\begin{array}{l}\text { Specimen } \\
\text { Uncoated Fe }\end{array}$ & Immersion Medium & k(deg) \\
\cline { 2 - 3 } $\begin{array}{l}\text { Coated Fe } \\
\text { Sat'd NaOH }\end{array}$ & 76 \\
\hline $\begin{array}{l}\text { Coated Fe with } \\
\text { deliberate holiday }\end{array}$ & $0.05 \mathrm{M} \mathrm{NaCl}$ & 83 \\
\hline $\begin{array}{l}\text { Coated Fe with } \\
\text { phosphate-chromate } \\
\text { surface pretreatment }\end{array}$ & $" 1$ & 73 \\
\hline
\end{tabular}

Coated Fe with " 8

$\mathrm{K}_{2} \mathrm{CrO}_{4}$ "islands"

Coated Fe with

$\mathrm{ZnCrO}_{4}$ "islands"

Coated Fe with 58

ZTOC* dispersed in coating

Coated Fe with

$\mathrm{K}_{2} \mathrm{CrO}_{4}$ dispersed in

coating

Coated $\mathrm{Fe}$ with 56

$\mathrm{SrCrO}_{4}$ located between

two layers of collodion

*Zinc tetraoxychromate

$\left[\mathrm{Zn}(\mathrm{OH})_{2}\right]_{4} \cdot \mathrm{ZnCrO}_{4}$ 



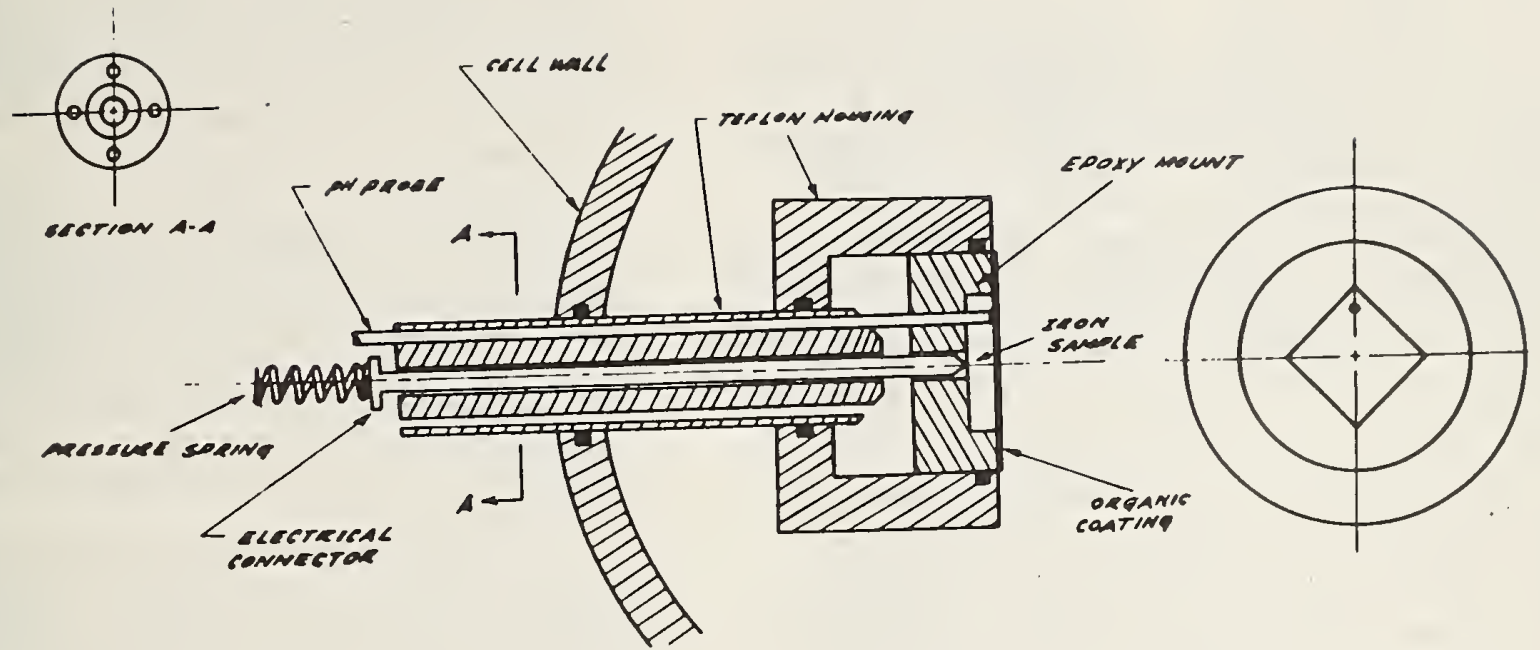

Fig. 1 - Schematic drawing showing detalls of the specimen mount

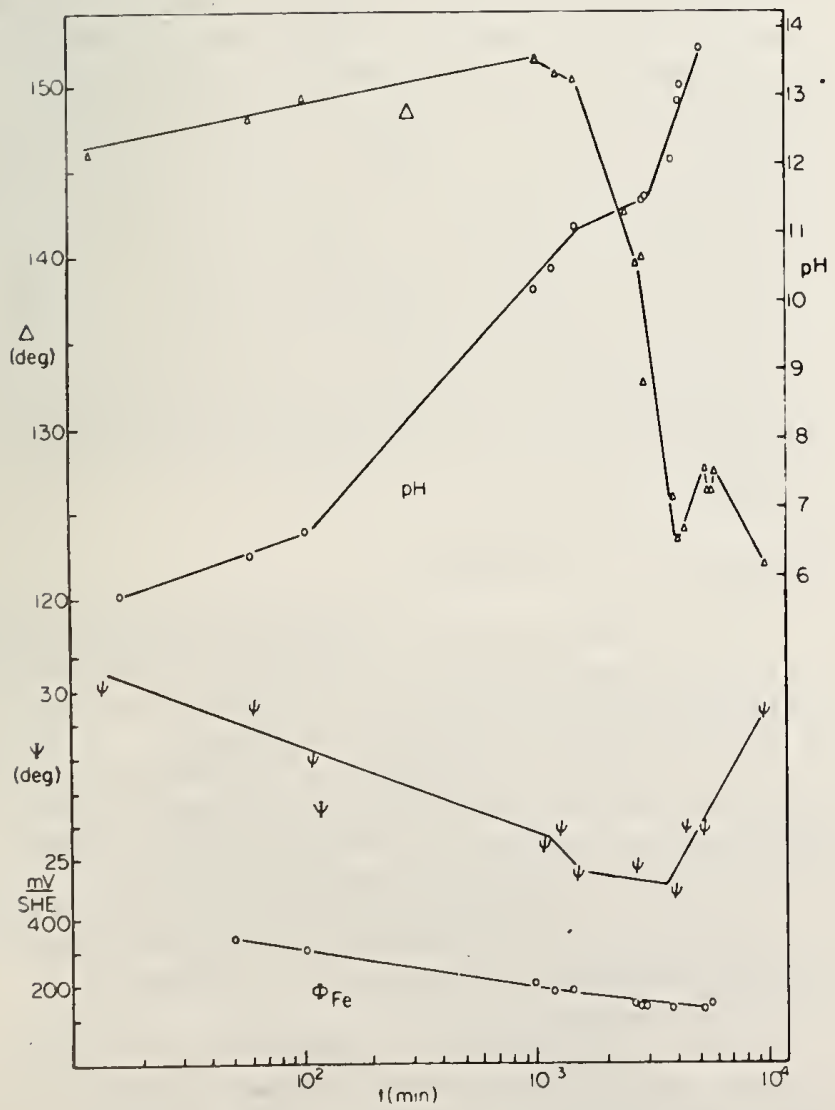

Fig. $2-\Delta$, relative phase retardation, $\psi$ relative amplitude reduction, $\mathrm{pH}$ and $\phi_{\mathrm{Fe}}$, potential of the Iron surface versus standard hydrogen electrode (S.H.E.) versus time for Fe with collodion in 0.05 $\mathrm{N} \mathrm{NaCl}$

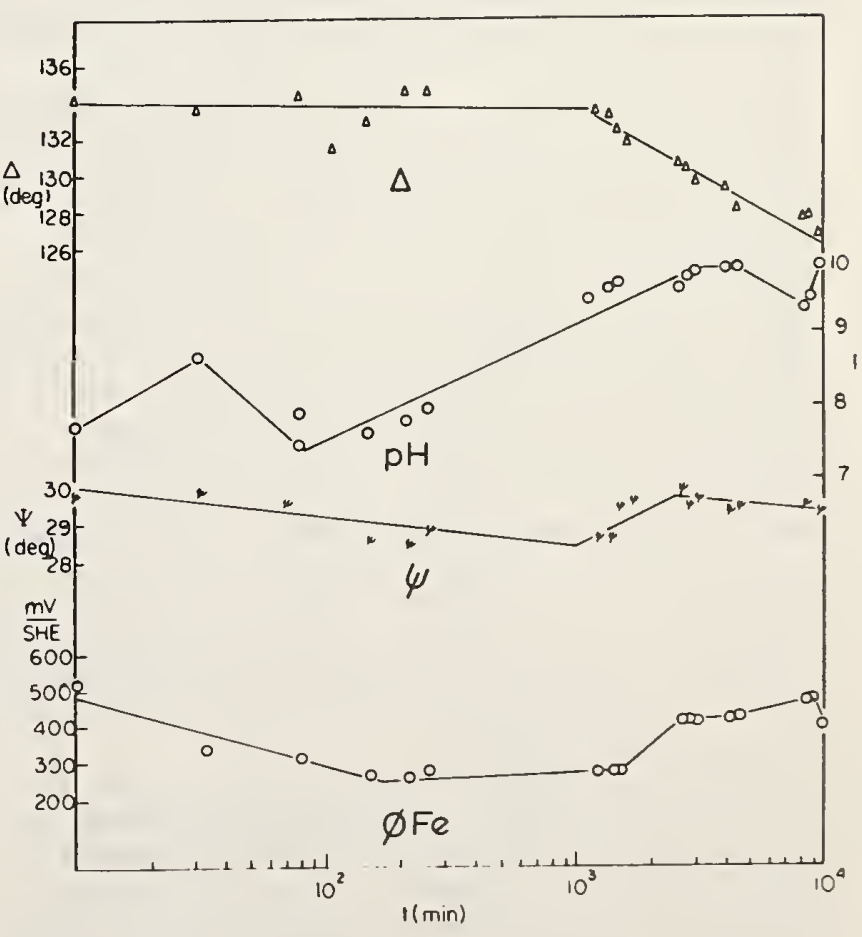

Fig. $3-\Delta, \psi, \mathrm{pH}$ and $\phi_{F e}$ versus time for $F e$ with collodion and $\mathrm{K}_{2} \mathrm{CrO}_{4}$ islands in $0.05 \mathrm{~N} \mathrm{NaCl}$ 
be small for films $<5 \mathrm{~nm}$ in thickness (6). Thus the thickness of these modified films can be estimated with reasonable confidence using parameters for $\mathrm{Fe}_{2} \mathrm{O}_{3}$.

Preliminary results from uncoated fron in a simulated sub-coating environment of $\mathrm{pH} 15$ (sat'd $\mathrm{NaOH}), 0.05 \mathrm{M} \mathrm{K}_{2} \mathrm{CrO}_{4}$ and $0.05 \mathrm{M} \mathrm{NaCl}$ show a change in $\Delta$ of which approximately $1 / 3$ is due to oxide film growth and the remainder ascribed to surface roughening. The oxide film growth on uncoated $\mathrm{Fe}$ even in this highly alkaline environment was only $2.4 \mathrm{~nm}$ as compared to the typical 6 $\mathrm{nm}$ growth measured for coated iron in the absence of inhibitor. Additional simulated environment experiments with other inhibitors under a variety of conditions are currently in progress and will be the subject of a future publication.

During the first stage, oxygen, water, $\mathrm{Na}^{+}$ and $\mathrm{Cl}^{-}$permeate the coating. The dilute $\mathrm{Cl}^{-}$ medium thus generated promotes localized breakdown of the existing air-formed oxide film originally present on the metal surface. Active metal sites are exposed and iron oxidation is promoted in these regions. Less active portions of the surface serve as cathodic regions for the reduction of $\mathrm{O}_{2}$ to $\mathrm{OH}^{-}$. Hence the gradual rise of $\mathrm{pH}$ during the first stage.

As the $\mathrm{pH}$ reaches high values $(>13)$ other events can proceed depending upon the potential of the metal in its subcoating environment. For example, experiments with uncoated iron in saturaind sodium hydroxide solution ( $\mathrm{pH} \sim 15$ ) suggest that this potential may vary over the range from -900 to $-150 \mathrm{mV} \mathrm{S.H.E.} \mathrm{Under} \mathrm{these} \mathrm{conditions}$ iron can be brought into solution through the formation of either the $\mathrm{HFeO}_{2}$ or $\mathrm{FeO}_{4}^{-2}$ ions and oxide film can grow, the oxidation of $\mathrm{HFeO}_{2}$ being one source of $\mathrm{Fe}_{2} \mathrm{O}_{3}$. The experimental evidence from cathodic reductions of stripped iron specimens and from deliberate electrochemical metal smoothing indicate that both surface roughening and oxide film growth phenonena occur under the coating and are primarily responsible for the large decreases observed in the $\Delta$ parameter during the second stage. Thus the high $\mathrm{pH}$ environment and concomitant decreases in the $\Delta$ parameter occur only when active corrosion is undetway somewhere on the surface of the coated metal. The new technique serves to detect the presence of serious subcoating corrosion and provides a measure of the overall kinetics for some of the sub-coating processes.

The implications of the observed surface roughening and oxide film growth phenomena for coating failure mechanisms remains somewhat speculative at this point. For the case of an intact coating, one might envision the inftial formation of small, "two dimensional" localized. corrosion cells as a result of $\mathrm{O}_{2}$, water and $\mathrm{Cl}^{-}$ permeation through the coating. The development of these cells may entail local delaminations of the coating. Anodic and cathodic regions develop within the cells, the anodic/cathodic surface area ratio being very small due to a paucity of active sites.* Thus much of the local cell area

*The limitation of active sites may be related to the number of susceptible crystal planes at the surface. For example, the iron $\{110\}$ plane shows a higher tendency toward passive film breakdown and pitting than do other crystal faces. 7,8,9 develops an alkaline environment which is conductve to surface roughening and oxide film growth. Topographical and possible compositional changes of the substrate surface promote more extensive coating delamination and lead to the coalescence of local cells into larger units. These events probably occur during the first stage noted in the experiments.

The anodic and cathodic reactions continue to promote the enlargement of the delaminated regions by the processes already described and the active area gradually comes within the sensitivity boundary of the ellipsometer. These events are then detected as the second stage. It is believed that by the time the second stage is observed ellipsometrically, the sub-coating corrosion processes are widespread over the specimen face.

As corrosion products build up in anodic areas they contribute to the stresses which finally cause coating rupture. With relatively free access to the electrolyte at the rupture site, the anodic activity accelerates and the electrolyte $\mathrm{pH}$ in cathodic regions may exceed 14. Experiments with collodion coated $\mathrm{Au}$ in $\mathrm{NaOH}$ at $\mathrm{pH} 15$ indicate coating decerioration after prolonged exposure. This deterioration may be partially responsible for the erratic behavior of $\Delta$ noted during the third stage.

The effects noted in the presence of $\mathrm{K}_{2} \mathrm{CrO}_{4}$ inhibitor are a generally lower sub-coating $\mathrm{pH}$ and comparatively less surface roughening and oxide film growth. This is consistent with the reported behavior of $\mathrm{CrO}_{4}{ }_{2}$ in supressing anodic dissolution of iron through the formation of an effective passive film. Under these conditions, the cathodic reduction of $\mathrm{O}_{2}$ must also be supressed and the sub-coating environment becomes only mildly alkaline. Therefore surface roughening and oxide film growth are also attenuated. Presumably this minimization of substrate topographical and constitutional changes translates into reduced coating delamination and hence longer coating life.

\section{SUMMARY AND CONCLUSIONS}

(1) The combined ellipsometric-electrochemical technique provides an effective, non destructive, In situ approach to the study of corrosion processes under transparent coatings.

(2) The studies reveal the growth of oxide film and surface roughening on those portions of the substrate under the coating which are subjected to a highly alkaline environment.

(3) It is proposed that the initial changes in topography and possibly in the constitution of the substrate surface may contribute to coating delamination.

(4) The presence of inhibitors such as $\mathrm{K}_{2} \mathrm{CrO}_{4}$ attenuates active dissolution of 1 ron and thus suppresses $\mathrm{OH}^{-}$buildup. The resultant attenuated film growth and surface roughening can be monitored ellipsometrically, thus suggesting that the new technique may be a valuable tool for the evaluation of Inhibitor performance.

\section{ACKNOWLEDGEMENT}

This paper is reproduced from "Proceedings of the International Conference on Corrosion 
Control by Organic Coatings", Henry Leidheiser, Jr., ed., National Association of Corrosion Engineers, Houston TX, (1981), with the kind permission of the editor.

\section{REFERENCES}

1. Henry Leidheiser, Jr. "Progress in Organic Coatings," (1979) 79.

2. J. J. Ritter and J. Kruger, "Surface Science," 1980 , in press.

3. J. Kruger, "Corrosion," (1966), 88.
4. F. P. Fehlner and N. F. Mott, "Oxidation of Metals," (1970), 59.

5. J. E. O. Mayne and M. J. Pryor, "J. Chem. Soc." (1949) 1831.

6. J. Kruger, "Advances in Electrochemistry and Electrochemical Engireering," R. H. Muller, ed., Vol 9, (1973), J. Wiley and Sons, p 250.

7. J. Kruger, "J. Electrochem Soc." (1959), 763.

8. J. Kruger, "J. Electrochem Soc." (1963), 654.

9. C. L. Foley, J. Kruger and C. J. Bechtholt, "J. Electrochem Soc.," (1967) 994. 


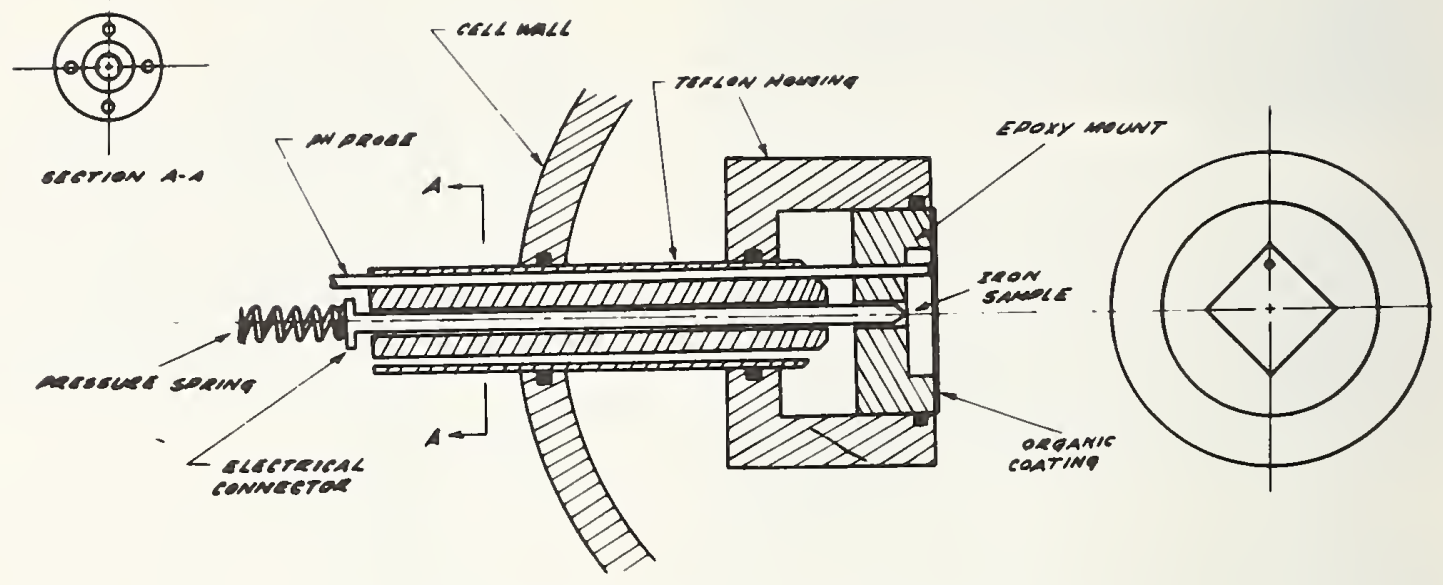

Fig. 1 - Schematic drawing showing details of the specimen mount

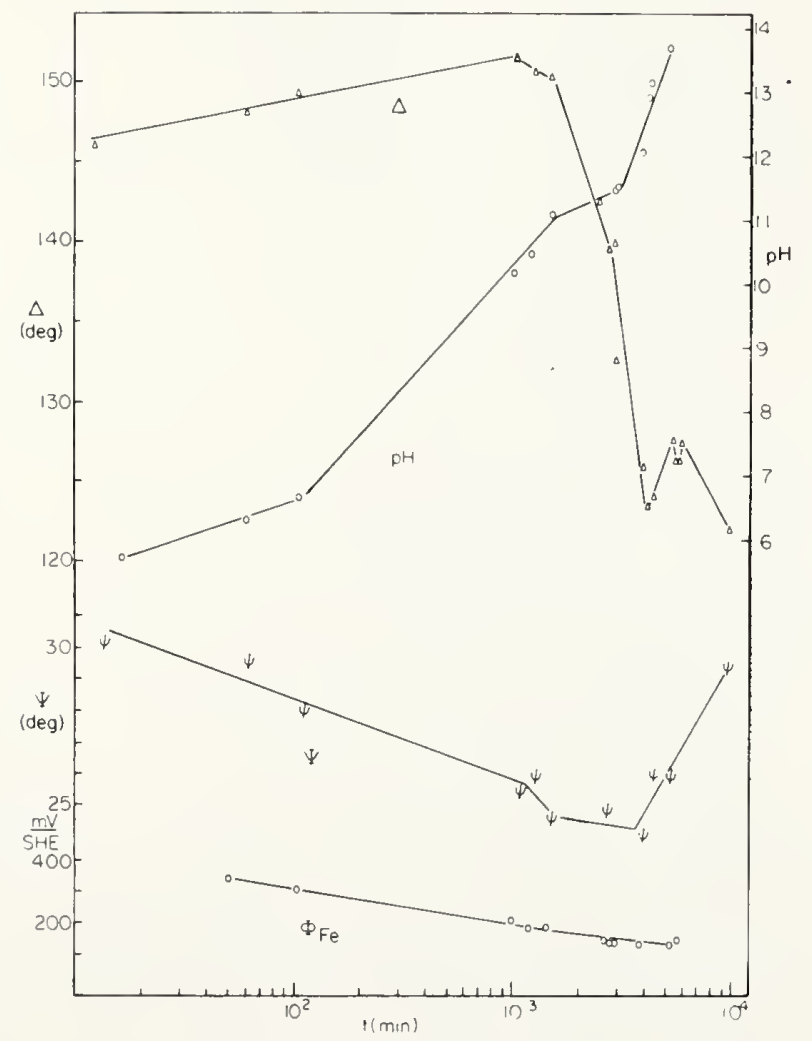

Fig. 2 - $\Delta$, relative phase retardation, $\psi$ relative amplitude reduction, $\mathrm{pH}$ and $\phi_{\mathrm{Fe}}$, potential of the Iron surface versus standard hydrogen electrode (S.H.E.) versus time for Fe with collodion in 0.05 $\mathrm{N} \mathrm{NaCl}$

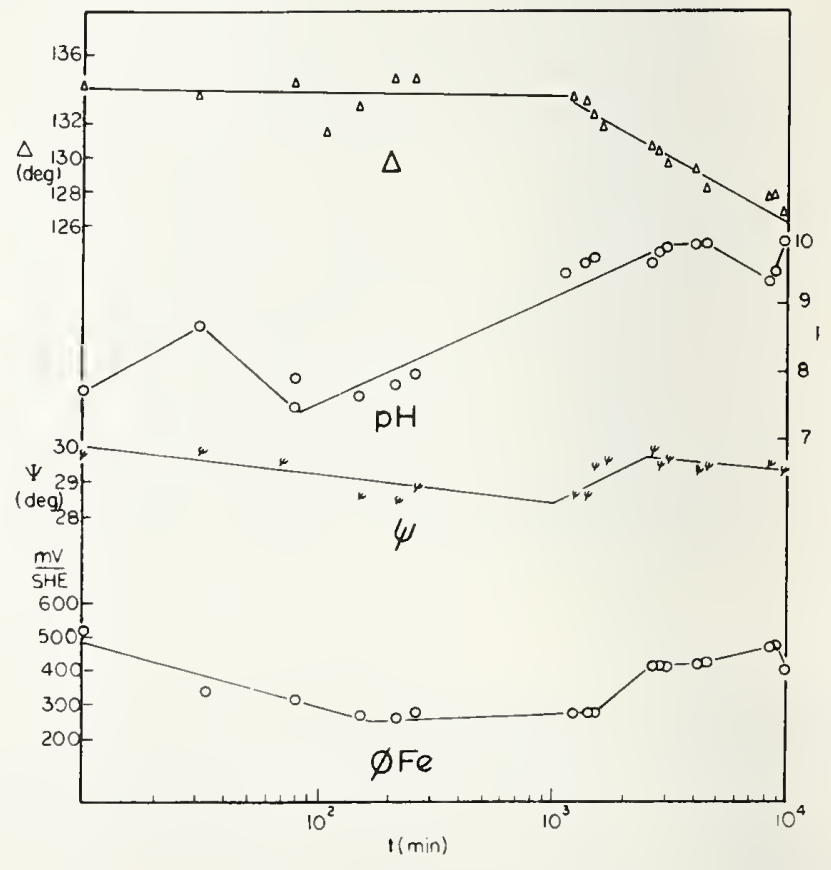

Fig. $3-\Delta, \psi, \mathrm{pH}$ and $\phi_{\mathrm{Fe}}$ versus time for $\mathrm{Fe}$ with collodion and $\mathrm{K}_{2} \mathrm{CrO}_{4}$ islands in $0.05 \mathrm{~N} \mathrm{NaCl}$ 
[Part II - To be submitted to CORROSION (1981).]

Abstract

The corrosion of metals protected by organic coatings is an incompletely understood phenomenon. Recent investigations by an in situ ellipsometricelectrochemical technique combined with microanalytical studies have provided new insights into the destructive processes. Events such as the roughening of the metal surface, chloride ion accumulation and the thickening of the surface oxide have been detected under the coating and are interpreted in terms of the chemistry which develops between the microenvironment and the substrate. 


\section{AN EXAMINATION OF SOME OF THE ASPECTS OF THE CORROSION OF IRON PROTECTED BY A CELLULOSE NITRATE COATING \\ J. J. Ritter and M. J. Rodríguez \\ Chemical Stability and Corrosion Division \\ National Bureau of Standards \\ Washington, D. C. 20234}

Introduction:

The corrosion of metals protected by organic coatings represents an extensive practical problem whose fundamentals are poorly understood. Studies in these laboratories have been designed to probe some of the basic aspects of this problem and elucidate some of the events which occur at the coating-substrate interface.

A combined ellipsometric-electrochemical technique, developed at NBS, has been used for the nondestructive, in situ detection of corrosion events occurring at the surface of an iron specimen protected by a transparent cellulose nitrate coating.* For this system, the predominant phenomena detected include the development of a highly alkaline subcoating environment, a roughening of the metallic surface, an increase in the

*The technique involves the passage of elliptically polarized light through the transparent coating and reflection from the substrate surface while a miniature $\mathrm{pH}$ probe simultaneously monitors the environment at the coating-substrate interface. Changes in the phase $(\delta \Delta)$ and amplitude $(\delta \psi)$ of the reflected light have been shown to be indicative of alterations in surface texture (roughness) and changes in the thickness of the surface oxide film. The optical system in its present configuration is relatively insensitive to changes in the cellulose nitrate coating and to the development of the microenvironment. Thus, the technique is of value in studying the behavior of the substrate under the coating as the corrosion process proceeds. 
thickness of the metal surface "oxide" film, and an accumulation of $\mathrm{Cl}^{-}$ ions under the coating. The results of these investigations affirm that the subcoating microenvironment, i.e., the thin liquid layer which gradually forms at the coating-substrate interface, takes an important role in the subcoating corrosion process. It is the purpose of this note to examine the subcoating phenomena in terms of the chemistry which. ensues between this microenvironment and the substrate.

Experimental: The details of the ellipsometric-electrochemical measurement technique have been presented previously. ' In brief, the coated iron sample is monitored ellipsometrically and electrochemically while immersed in a $0.05 \mathrm{M} \mathrm{NaCl}$ solution. After approximately one week, the iron sample is removed from the ellipsometer cell, and it is transferred to a 100 percent humidity chamber. It is carefully rinsed with chloridefree distilled water, and the excess of external liquid is removed with absorbent filter paper. The organic coating is incised with a sharp scalpel, and an aliquot is removed from the blister by means of a micropipet. The aliquot (usually from one to eight microliters) is transferred to a volumetric flask, and it is diluted with low chloride content $\left(10^{-12} \mathrm{M}\right)$ distilled water.

This chloride solution is analyzed potentiometrically ${ }^{2}$ using the method adapted from Cunningham, Kirk and Brooks ${ }^{3}$. An aliquot is treated with dilute sulfuric acid, until the final acid concentration is (approximately) 0.3 to $0.4 \mathrm{~N}$, then it is titrated with standard silver nitrate. The end point is determined potentiometrically using a silver-silver oxide and a silver-mercury amalgam electrode pair. The error in the analysis is of the order of \pm 0.5 percent for $0.5 \mu \mathrm{g}$ of chloride. 
Results and Discussion

I. The Concentration of $\mathrm{Cl}^{-}$in the Subcoating Microenvironment.

It is generally held that a viable subcoating microenvironment can exist in a water layer as thin as $3 \mathrm{~nm}$. In the collodion-coated iron systems this microenvironment will often achieve macroscopic dimensions after about one week so that from 1 to $8 \mu 1$ of liquid can be withdrawn by micro techniques and subjected to analyses. Preliminary results of $\mathrm{Cl}^{-}$analyses on these microenvironment liquids indicate a $\mathrm{Cl}^{-}$ion concentration three or four times that of the bulk immersion medium. Evidently there exists an effective driving force to promote the migration of $\mathrm{Cl}^{-}$ions. This driving force may be similar to that which promotes the concentration of $\mathrm{Cl}^{-}$ions in pits and crevices. With this idea in mind, we may explore the development of corrosion on an organically coated iron specimen through the following steps:

(1) The initiation of corrosion due to any number of causes such as a defect in the coating, mechanical rupture of the coating, the presence of a subcoating soluble surface impurity which promotes coating rupture through the generation of osmotic pressure, etc.

(2) In the early stages, anodes and cathodes develop in proximity and as iron goes into solution it is rapidly precipitated out as a hydroxide due to appreciable concentrations of $\mathrm{OH}^{-}$ions (from the cathodic reduction of $\mathrm{O}_{2}$ ) nearby. The hydroxide corrosion products form into a hollow cone which ultimately becomes a barrier to the free transport of neutral species such as $\mathrm{O}_{2}$. 
(3) Lack of oxygen to support the cathodic reaction would ordinarily stop the corrosion process. However, elsewhere on the specimen surface sufficient oxygen, water and some ions have penetrated the coating and these regions now become cathodic sites. The system continues to corrode with anodes and cathodes physically isolated from each other.

(4) In the anodic regions, the $\mathrm{Fe}^{+2}$ ions initially formed undergo hydrolysis to produce additional solid corrosion products plus $\mathrm{H}_{3} \mathrm{O}^{+}$ions. The $\mathrm{H}_{3} \mathrm{O}^{+}$ions require negative counter ions, and for the coated metal system, sources are limited. For example, the cathodically produced $\mathrm{OH}^{-}$ions are maintained captive near their production sites by the organic coating. However, chloride ions are abundant in the bulk solution and tend to migrate into the hollow cone of corrosion products to maintain charge neutrality (Fig. 1). This process is identical to that proposed in crevice or pitting corrosion. ${ }^{4}$

(5) The migration of $\mathrm{Cl}^{-}$into the anodic regions would leave an excess of positively charged $\mathrm{Na}^{+}$in the bulk except that these ions will readily penetrate the coating at the cathodic sites and act as counter ions to the $\mathrm{OH}^{-}$species. Watts and Castle have verified the presence of significant amounts of $\mathrm{Na}$ in areas of cathodic delamination through the use of surface analysis techniques. ${ }^{5}$ The migration of the ions accomplishes the charge transport necessary to sustain the corrosion reactions.

(6) At this point there are distinct regions on the specimen with very different chemical compositions. The anodes will be 
quite acidic and hold large quantities of $\mathrm{Cl}^{-}$while the cathodes will be very basic and rich in $\mathrm{Na}^{+}$. Thus it is quite possible that the superimposed processes of Fe dissolution and surface film thickening observed in the highty alkaline regions under the coating occur in a low $\mathrm{Cl}^{-}$environment.

(7) As the coating system deteriorates, a breakthrough between anodic and alkaline areas may occur with concomitant neutralization reactions between $\mathrm{H}_{3} \mathrm{O}^{+}$and $\mathrm{OH}^{-}$as we 11 as dilution of the $\mathrm{Cl}^{-}$ ion concentration. Since the liquid volumes involved in such a "breakthrough" are likely to be smal1, it is very reasonable to expect that the resultant $\mathrm{Cl}^{-}$concentration would still be higher than that of the bulk solution. Experimental evidence for such a breakthrough is shown by the $\mathrm{pH}$ behavior in Fig 2 and is schematically represented in Fig. $1 \mathrm{c}$.

II. Surface Roughening and Surface Film Thickening.

A preliminary analysis of the ellipsometrically observed subcoating phenomena of surface roughening and surface film thickening presents an enigma. The typical regions of a specimen under ellipsometric examination are the focal points of the cathodic reduction of oxygen, yet in these regions we observe surface roughening; i.e., the uneven dissolution of metal, which is definitely an anodic process. This disparity can be resolved by postulating the movement of cathodic activity from one local area to another.

The processes are summarized in the following steps:

(1) The arrival of sufficient oxygen and water in a local subcoating region to support the cathodic reaction. 
(2) Product $\mathrm{OH}^{-}$ions from the oxygen reduction reaction are kept captive in the local microenvironment by the organic coating.

(3) At high pH (14 or 15) the cathodic activity in this local area ceases, and iron dissoives. Thus the metal surface roughens.

(4) The corrosion activity continues with reductive support from new cathodic sites which begin to emerge under the coating on other areas of the specimen surface.

(5) The soluble iron species are held captive in the high pH region by the organic coating. When a critical species concentration is achieved, precipitation occurs and the surface firm thickens.

(6) Each emerging cathodic site progresses through steps 1,2,3 and 5 and the ellipsometer integrates these processes over a finite region of the specimen surface.

While the exact species and mechanisms by which these processes occur have not yet been identified, the chemistry of the dihypoferrite iron $^{6}$, $\left(\mathrm{HFeO}_{2}{ }^{-}\right)$, offers a thermodynamically reasonable explanation.

$$
\begin{gathered}
\mathrm{Fe}+3 \mathrm{OH}^{-} \longrightarrow \mathrm{HFeO}_{2}{ }^{-}+\mathrm{H}_{2} \mathrm{O}+2 \mathrm{e} \text { (iron dissolution/surface roughening) } \\
2 \mathrm{HFeO}_{2}{ }^{-} \longrightarrow \mathrm{Fe}_{2} \mathrm{O}_{3} \downarrow+\mathrm{H}_{2} \mathrm{O}+2 \mathrm{e} \text { (oxidation, precipitation/surface film } \\
\text { thickening) }
\end{gathered}
$$

Ellipsometrically, the behavior of uncoated iron in high pH environments is very similar to that of coated iron undergoing active corrosion. This similarity is illustrated in Fig. 3. Surface roughening is a regular feature of uncoated iron immersed in saturated $\mathrm{NaOH}$ both with 
and without $\mathrm{Cl}^{-}$. However, surface film thickening is not typically observed in these simulated environments. This difference in behavior between coated iron undergoing corrosion and uncoated iron reacting in a simulated subcoating medium is taken as support for the dissolutionprecipitation mechanism presented earlier. Metal dissolution in alkaline media takes place in both cases, but the dissolved iron species are held captive by the organic coating in the one case while in the second case these species simply diffuse away so that adequate concentrations for precipitation do not develop.

Summary

In this note we have developed some preliminary views to encompass the results of our ellipsometric-electrochemical and microanalytical measurements on a coated iron system. It has become apparent during this work that the nature of the subcoating microenvironment is an important factor to the course of corrosion. The ellipsometer provides a nonintrusive means of studying surface events at the molecular level and probes the results of the chemistry which occurs between the microenvironment and the substrate. It is this chemistry which is responsible for surface roughening and oxide film thickening.

The superimposed process of $\mathrm{Cl}^{-}$concentration follows directly from the tendency of mobile ionic systems to achieve electroneutrality. This part of the subcoating phenomena is identical to that which prevails during crevice or pitting corrosion. The feature which differentiates the coated metal system from a pit or crevice system is the presence of the organic coating which can act as a semipermeable barrier to the migration of materials. 
While the present studies deal primarily with substrate changes as a result of interaction with the microenvironment, the sequence of these changes with respect to the rupture of polymer-substrate bonds is not yet clearly defined. This problem is directly related to the question of whether changes in surface texture or oxide properties constitute a mechanism for coating-substrate bond failure. We are currently implementing modifications to the ellipsometric-electrochemical technique which may give further insights to this important question.

\section{Acknowledgement}

We are grateful to the Office of Naval Research which supported this work under O.N.R. contract 1889 NRO 36082. 


\section{$\underline{\text { References }}$}

1. J. J. Ritter and J. Kruger, Surface Science, 96, p. 364 (1980).

2. Paul Kirk, Quantitative Ultramicroanalysis, John Wiley \& Sons, Inc., New York, NY (1950).

3. B. Cunningham, P. L. Kirk, and S. C. Brooks, J. Biol. Chem., 139, p. 11 (1941).

4. M. G. Fontana and N. D. Greene, Corrosion Engineering, McGraw-Hill, New York, pp. 41, 51 (1978).

5. J. E. Castle and J. F. Watts, Proceedings of the International Conference on Corrosion Control by Organic Coatings, Henry Leidheiser, Jr., (ed.), National Association of Corrosion Engineers, Houston, Texas (1981).

6. M. Pourbaix, Atlas of Electrochemical Equilibria in Aqueous Solutions, Pergamon Press, NY, p. 310 (1966). 
Figure Captions

1. a. A summary of the equations proposed for subcoating events leading to surface roughening, oxide film thickening and the promotion of $\mathrm{Cl}^{-}$ion accumulation.

b. Schematic showing $\mathrm{Cl}^{-}$ion entry into the hollow cone of anodic corrosion products in the presence of a remote cathode. c. Schematic suggesting one mode of anodic-cathodic "breakthrough".

2. Experimental curve showing change in the ellipsometric parameter $\Delta$ and $\mathrm{pH}$ as subcoating process proceeds. Steady decline of $\mathrm{pH}$ after $1200 \mathrm{~min}$. indicates a "breakthrough" between anodic and cathodic sites in the vicinity of the subcoating $\mathrm{pH}$ probe.

3. Schematic showing the similarities in ellipsometric behavior with time for uncoated iron at $\mathrm{pH} \sim 15$ and coated iron undergoing corrosion in $0.05 \mathrm{M} \mathrm{NaCl}$. 


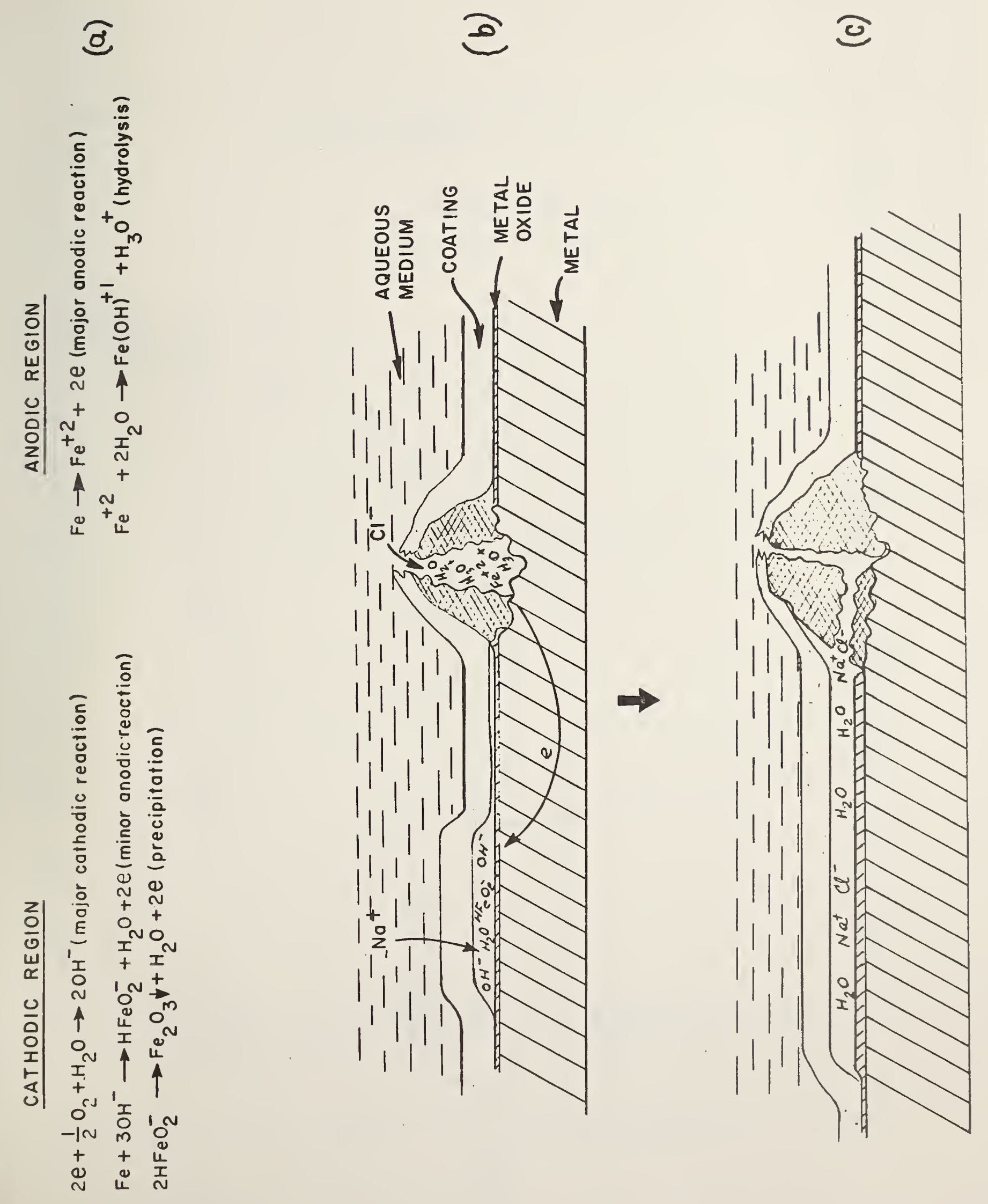




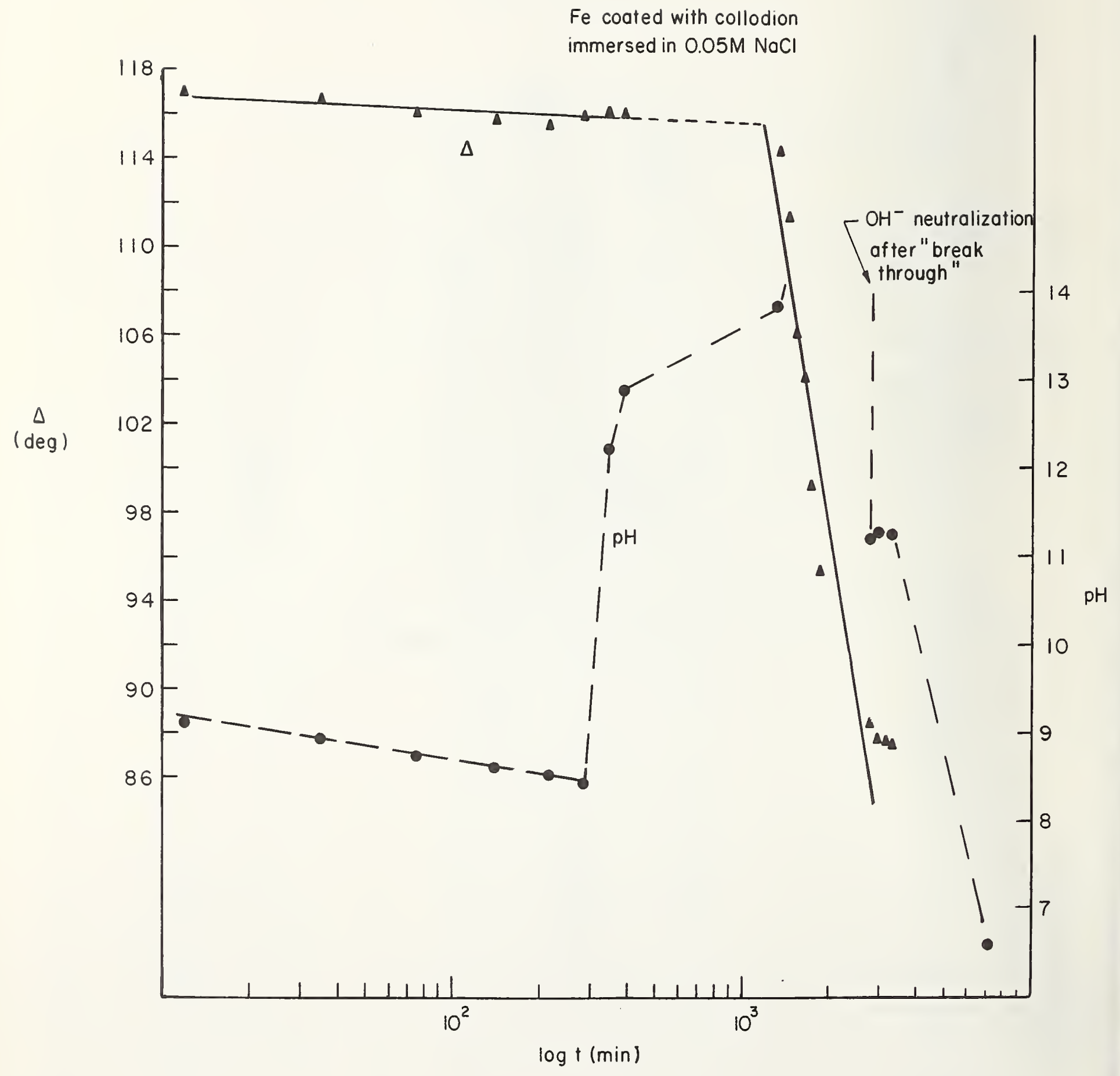




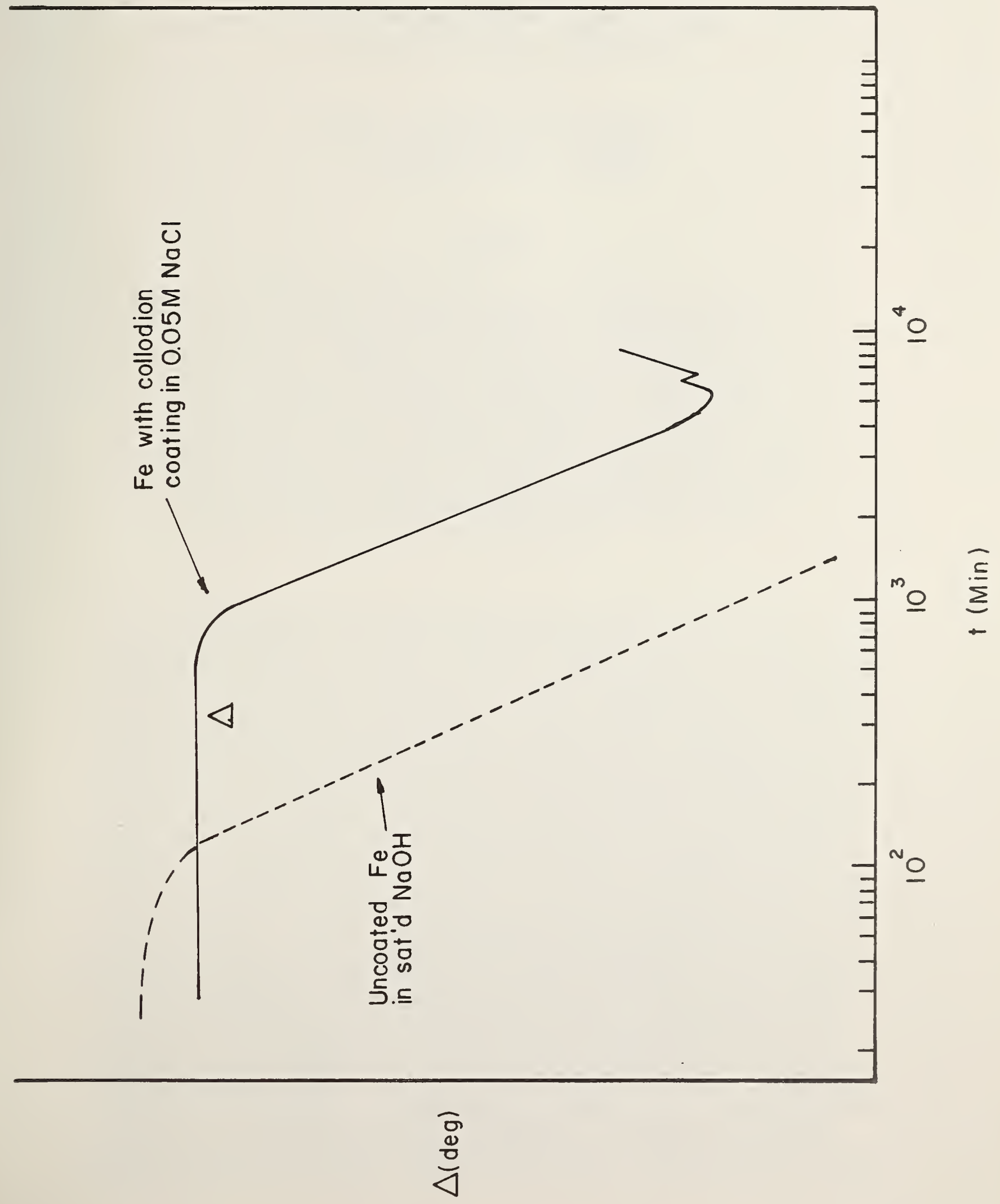


[Part III - To be published in the proceedings of a symposium commemorating the 75 th brithday of $\mathrm{H}$. H. Uhlig by the Electrochemical Society at its National Meeting in Denver Colorado in October 1981.]

DISSOLUTION OF PASSIVE FILMS ON IRON

IN NEARLY NEUTRAL SOLUTIONS

\author{
J. Kruger \\ Center for Materials Science \\ National Bureau of Standards \\ Washington, D.C. 20234
}

\begin{abstract}
A description is given of a study of the dissolution of passive films formed by potentiostatic anodic oxidation of iron in sodium borate-boric acid solutions. Using an ellipsometric-potentiostatic technique, four different potential regions were identified where different dissolution behavior could be observed. Two different dissolution modes were found at potentials in the passive region; one dissolution mode at potentials at or slightly below the Flade potential, and one mode at potentials where cathodic reduction becomes possible.
\end{abstract}

A great deal of attention has been paid to the formation of passive films on iron [see (1) for reviews of the subject], but considerabiy less has been written on the details of the dissolution of these films, a process of equal importance to an understanding of corrosion processes. The studies in the literature on the dissolution of the passive film mainly deal with dissolution in acid solutions (2) and involve either galvanostatic (3) or steady state open circuit (4) conditions that produce film thinning. One major contribution to this area was that made by Prof. Uhlig, in whose honor this and the other papers of this symposium are dedicated; this was his study with Peter King of the Flade potential (5) in 1959. The work described here differs from past efforts in that dissolution is carried out under potentiostatic control (fixed driving force) and in nearly neutral solutions. The rationale for such an approach was to derive insights into the role played by reverse fields on dissolution and to, thereby, seek to distinguish between field and chemical dissolution effects that result in passive film thinning. In more acidic solutions, it is likely that chemical dissolution would be a more expected mode of film thinning than in neutral or alkaline environments. There are two other reasons for studying dissolution in nearly neutral solutions: (a) the dissolution process is slower than in acidic media and, hence, easier to study; and, (b) a nearly neutral solution is more closely related 
to a number of natural environments (e.g., natural waters) in which an understanding of protective film dissolution is important to corrosion prevention technology.

\section{Experimental Approach}

The metals (polycrystalline and single crystal iron) and solutions (sodium borate-boric acid solutions) are described elsewhere (6). The ellipsometric-potentiostatic technique used is also given in previous papers $(6,7)$. To study dissolution processes, these techniques were used in the following manner: A passive film was grown on an iron surface by polarizing that surface by means of a potentiostat in borate buffer solutions at either $\mathrm{pH} 8.1$ or $\mathrm{pH} 8.8$ at a potential well into the passive region $0.8 \mathrm{~V}$ (SCE). After the film growth has proceeded to the point where the rate of growth was one $\AA / h r$ or less (a few hours), the potential was set by a potentiostat at a selected potential below $0.8 \mathrm{v}$ and the change (if any) of the thickness of the film on the iron surface observed by means of an ellipsometer. In this way, the rate of dissolution or other changes on the metal surface could be observed as a function of potential.

\section{Dissolution Regions}

Four distinct potential regions were identified where different dissolution modes were observed. These regions were as follows: Region I--from the film growth potential $0.8 \mathrm{v}$ to $-0.2 v$; Region II--from $-0.2 v$ to $-0.5 v$; Region III--from $-0.5 v$ to $-0.7 v$; and, Region IV--from $-0.7 v$ to $-0.8 v$. In Fig. 1 , these four regions are shown in a plot of steady state film thickness (the nearly constant values reached after a few hours at a potential lower than the film formation potential) versus the potential that the iron was brought to by means of a potentiostat after film formation at $0.8 \mathrm{v}$ (SCE). The characteristics of the four regions shown in Fig. I will now be described and discussed.

\section{Region I}

In going from the film formation potential $0.8 \mathrm{v}$ to any lower potential in Region I, no changes in film thickness were observed. In fact, since after one hour the growth of a film at $0.8 v$ was still going on, lowering the potential to a Region I value stopped this ongoing growth but did not cause dissolution. If one assumes that anodic film growth on iron is a field assisted process, involving both forward and backward fields [see 
Young (8)]. Region I behavior would indicate that the forward field was sufficiently high in this potential region to resist dissolution. Growth was stopped, however, because the forward field was not high enough at a potential lower than the formation potential $(0.8 \mathrm{~V})$.

Figure 2 illustrates the role of the field (overpotential, $\eta$, divided by the film thickness, $x$ ) in continuing, stopping, or in going into Region II, reversing film growth. During the first ten minutes, the film is growing at a potential of $0.8 \mathrm{v}$. When the potential is lowered to $0.4 \mathrm{~V}$ (a potential in Region I), the growth stops, and the thickness remains constant, because the overpotential, and hence the field, is too low to promote further growth. When the potential is again raised to the original formation potential $0.8 \mathrm{v}$, growth starts up again, because $n / x$ is aga in apparently large enough to cause further growth. When the potential is dropped to a value in Region II, $-0.2 v$, not only is growth stopped, but the film starts to thin. Going to $0.8 \mathrm{v}$ again causes growth to resume. The experiment illustrated in Fig. 2 strongly suggests that a field across the passive film can play a role in causing growth, stopping growth and, as the results to be described next for Region II indicate, promoting dissolution.

\section{Region II}

As indicated by the results shown in Fig. 2, Region II is an interval of potentials where slow dissolution of a film formed at $0.8 \mathrm{v}$ takes place. Figure 3 shows the progress of such dissolution for two buffered borate solutions, $\mathrm{pH} 8.8$ and $\mathrm{pH} 8.1$. Continuing the suggestion made in the discussion of Region I that the field across the passive film plays an important role in growth and dissolution, it is now useful to examine in more detail the interplay of the forward and backward fields involved in the formation of films by anodic oxidation. Young (8) describes the anodic oxidation process as involving the movement of ions in an oxide lattice under the influence of an applied field. He describes two ion currents produced by a field; a forward current, $\vec{i}$, and a reverse current, $\vec{i}$. Making a number of simplifying assumptions, e.g., neglecting concentration gradients, Young calculates a ratio, $R$, of the forward to the backward ion currents as follows:

$$
R=\frac{\vec{i}}{\vec{i}}=\frac{\exp -[(W-q a E) / k t]}{\exp -[(W+q a E) / k t]},
$$


where $W=$ the activation energy for a mobile ion to jump from one lattice position to an adjacent position; $q=$ the charge on a moving ion; $a=$ the half barrier width or half jump distance; and, $T=$ the temperature.

Equation [1] can now be used to calculate $\mathrm{R}$ in order to examine whether the backward field would be expected to promote dissolution in Region II, but not in Region I.

Making the following assumptions:

(a) The equilibrium reaction for iron in a solution of $\mathrm{pH} 8.8$ is $3 \mathrm{Fe}+4 \mathrm{H}_{2} \mathrm{O}=\mathrm{Fe}_{3} \mathrm{O}_{4}+8 \mathrm{H}^{+}+8 \mathrm{e}^{-}$(this assumption is needed to calculate the overpotential used to calculate the field, E);

(b) W has the typical value of $1.0 \mathrm{ev}$ (8);

(c) The moving ion is $\mathrm{Fe}^{++}$and $\mathrm{q} . \mathrm{is}$, therefore, two;

(d) The value for a is $2.6 \AA$, as reported by Moshtev (9) for the passive films formed on iron in nearly neutral solutions;

(e) The temperature is $300^{\circ} \mathrm{K}$;

$R$ was found to have the values of:

$$
\begin{aligned}
& R \text { (for Region I potential } 0.4 v \text { ) }=4 \times 10^{5} \text {; } \\
& R \text { (for Region II potential }-0.35 v \text { ) }=181 \text {. }
\end{aligned}
$$

It can thus be suggested that the significant difference between Region I, where no dissolution is observed, and Region II, where slow dissolution is found, is that in Region II, the backward ion current or field which promotes dissolution is around. three orders of magnitude higher than it is for Region I. These results suggest that the ratio of $\vec{i} / \vec{i}(R)$ is more important than chemical dissolution for passive film thinning on iron in a nearly neutral solution.

To test this hypothesis, Region II dissolution was carried out in solutions with two different $\mathrm{pH}$ values ( 8.8 and 8.1 ). Since the overpotential is higher for the higher $\mathrm{pH}$, the ratio of the forward to the backward current should be higher for the films formed in the $\mathrm{pH} 8.8$ solution and the rate of dissolution, therefore, lower than that found for the $\mathrm{pH} 8.1$ solution. When $R$ is calculated for the two solutions, the following results are found: 


$$
\begin{aligned}
& R(\text { for } p H 8.8)=181 ; \\
& R(\text { for } p H 8.1)=107 .
\end{aligned}
$$

As Fig. 3 shows, the expected higher dissolution rate for the $\mathrm{pH} 8.1$ solution was observed experimentally.

Another factor besides $\mathrm{pH}$ that controls the rate of dissolution in Region II is the nature of the passive $f 11 \mathrm{~m}$. This nature is influenced by, among many other variables of formation, the time of growth. For example, the induction time for pit initiation depends strongly on the time that a passive $f i 7 m$ on iron is allowed to grow before it is exposed to breakdown conditions (10). As Fig. 4 shows, the Region II dissolution rate is also dependent on film growth times. The complete film (a film that was held at $0.8 \mathrm{v}$ long enough to reach steady state growth, a few hours) shows a lower dissolution rate than an incomplete film (a film that was held at $0.8 \mathrm{v}$ for a few minutes). These results indicate that another factor, the nature of the dissolving film, may play a role in the dissolution process in addition to that played by the forward and backward fields.

Finally, it should be pointed out that the potential where the transition between Region I and Region II occurs is near the potential called $E_{a}^{2}$ by Nagayama and Cohen (3). $E_{a}^{2}$ was the potential they found for iron in buffered borate solutions above which virtually. no ferrous ions were found in solution and below which detectable concentrations were found. If $R$, the value of the ratio of forward to backward ion currents, is important in determining whether passive film dissolution takes place, as suggested above, then it is responsible for the existence of $E_{a}^{2}$, and $E_{a}^{2}$ is the boundary potential between Region I and Region II.

\section{Region III}

This region straddles the active-passive transition, the Flade region. The optical results were not as straightforward as that observed for Regions I and II. Instead of the observation that the ellipsometric parameter $\Delta$ increased as film thickness decreased, as found in Region II, $\Delta$, the relative phase retardation, increased at the beginning of the dissolution process and then began to decrease (Fig. 5).

Earlier studies (7) have shown that the decrease was the result of surface roughening after the initial dissolution of the passive layer. Figure 5 suggests that the roughening, as sig- 
naled by $\frac{d \Delta}{d t}$, going from + to -, also occurred when the current went from + to -. This change in sign may indicate the transition from the passive to the active state. The earlier studies (7) also suggested, on the basis of rather speculative optical calculations, that the metal dissolution that resulted in surface roughening occurred at discrete sites, either to form pits or to attack the grain boundaries on the polycrystalline iron surface that was used.

To determine whether these suggestions had any merit, Region III dissolution was carried out on single crystal surfaces where, of course, there were no grain boundaries. Figure 6 shows the results obtained for two different orientations, (011) and (311). If grain boundaries are the only sites of attack, the reversal in the direction of change for $\Delta$ should not be observed. As Fig. 6 shows, this is what was observed for the iron surface with the (311) orientation. The (011) surface, however, did show the same reversal in direction of change for $\Delta$ that was observed for the polycrystalline iron surface. These results may not throw doubt on the interpretation of the optical results (7) described, because it has been found that the (011) orientation for iron is more susceptible to pitting attack than other orientations (11) and that the optical observations, therefore, do indicate the surface roughening that results from pitting.

\section{Region IV.}

This region contains potentials where the passive layer should be rapidly reduced. The ellipsometric measurements indicated this was so but also indicated that there are two rates of reduction (see Fig. 7). The first stage was more rapid than the final stage. These results confirm the galvanostatic reduction results of Nagayama and Cohen (3), who ascribed the two stages to the initial more rapid reduction of $\mathrm{\gamma Fe}_{2} \mathrm{O}_{3}$, followed by a slower reduction of $\mathrm{Fe}_{3} \mathrm{O}_{4}$.

\section{Summary}

1. Four potential regions of dissolution of the passive layer on iron have been identified.

2. The ratio of the forward to the backward currents produced by the field across the passive layer appears to be important in separating Region I from Region II. This observation suggests that Region II dissolution occurs because of field effects rather than being the result of chemical dissolution. 
3. Region III dissolution behavior involved both passive film dissolution and metal dissolution.

4. Region IV dissolution occurs in two stages, with the first stage being the more rapid of the two.

\section{Acknowledgement}

I am grateful to the Office of Naval Research, who supported part of this work under Contract NAONR 18-69 NRO 36-082. 
1. "Passivity of Metals", R. P. Frankenthal and J. Kruger, Eds., Electrochem. Soc., Princeton (1978).

2. K. J. Vetter and F. Gorn, Electrochim. Acta, 18, 321 (1973).

3. M. Nagayama and M. Cohen, J. Electrochem. Soc., 109, 781
(1962).

4. K. J. Vetter, ‥ Electrochem. Soc., 110, 597 (1963).

5. H. H. Uhlig and P. F. King, J. Electrochem. Soc., 106, I
(1959).

6. J. Kruger and J. P. Calvert, J. Electrochem. Soc., 114, 43
(1967).

7. J. Kruger, Corrosion, 22, 88 (1966). 8. L. Young, "Anodic Oxide Fi7ms", Academic Press, NY, 1961,
p. 15.

9. R. V. Moshtev, Electrochim. Acta, 16, 2039 (1971).

10. J. R. Ambrose and J. Kruger, Proc. Sixth Int1. Cong. on Metallic Corr., Amsterdam, NACE, Houston, 1972, p. 698.

11. J. Kruger, J. Electrochem. Soc., 106, 736 (1959). 


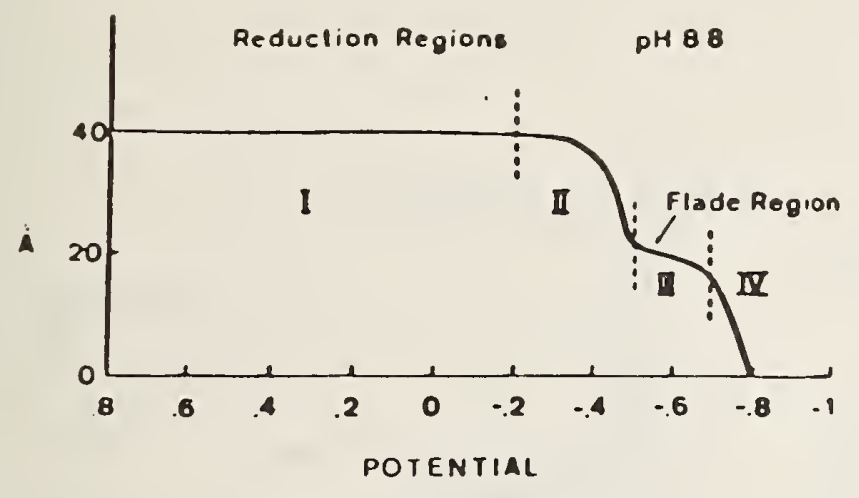

Fig. 1. The dissolution regions observed when a film formed by anodic oxidation at $0.8 \mathrm{v}$ (SCE) in buffered borate solution pH 8.8 is brought to a lower potential. The thickness values $\AA$ shown are the steady state values observed after a few hours when $d A / d t<I A / h r$.

Fig 2. The effect of changes of potential on film growth and dissolution in Region I, $\mathrm{pH}=8.8$.
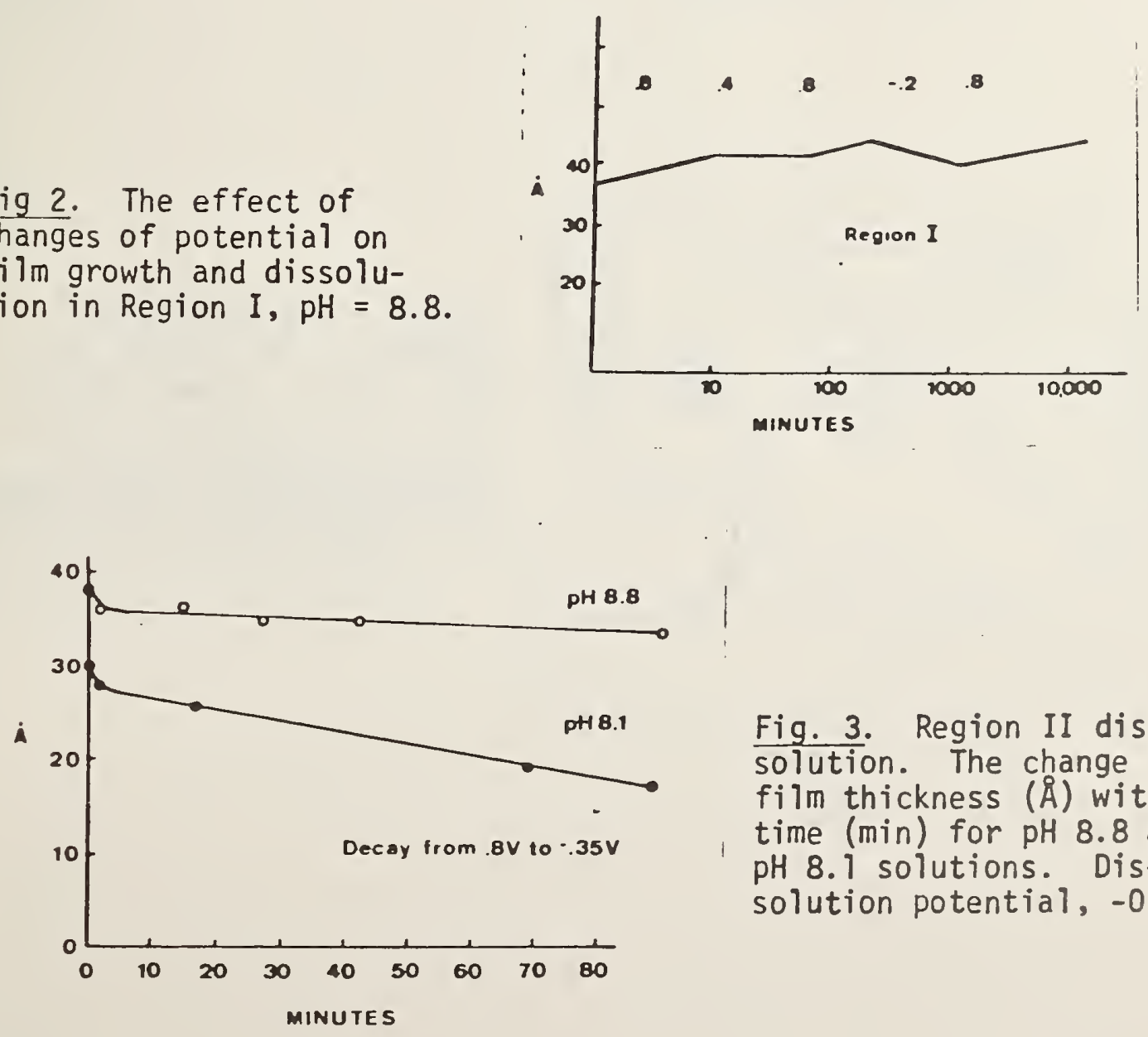

Fig. 3. Region II dissolution. The change in film thickness $(\AA)$ with time (min) for $\mathrm{pH} 8.8$ and pH 8.1 solutions. Dissolution potential, $-0.35 \mathrm{v}$. 
Fig. 4. The Region II dissolution of an incomplete (less than a few minutes growth at $0.8 \mathrm{v}$ ) and a complete film (growth at $0.8 \mathrm{v}$ for over one hour). Dissolution potential, $-0.35 v$.
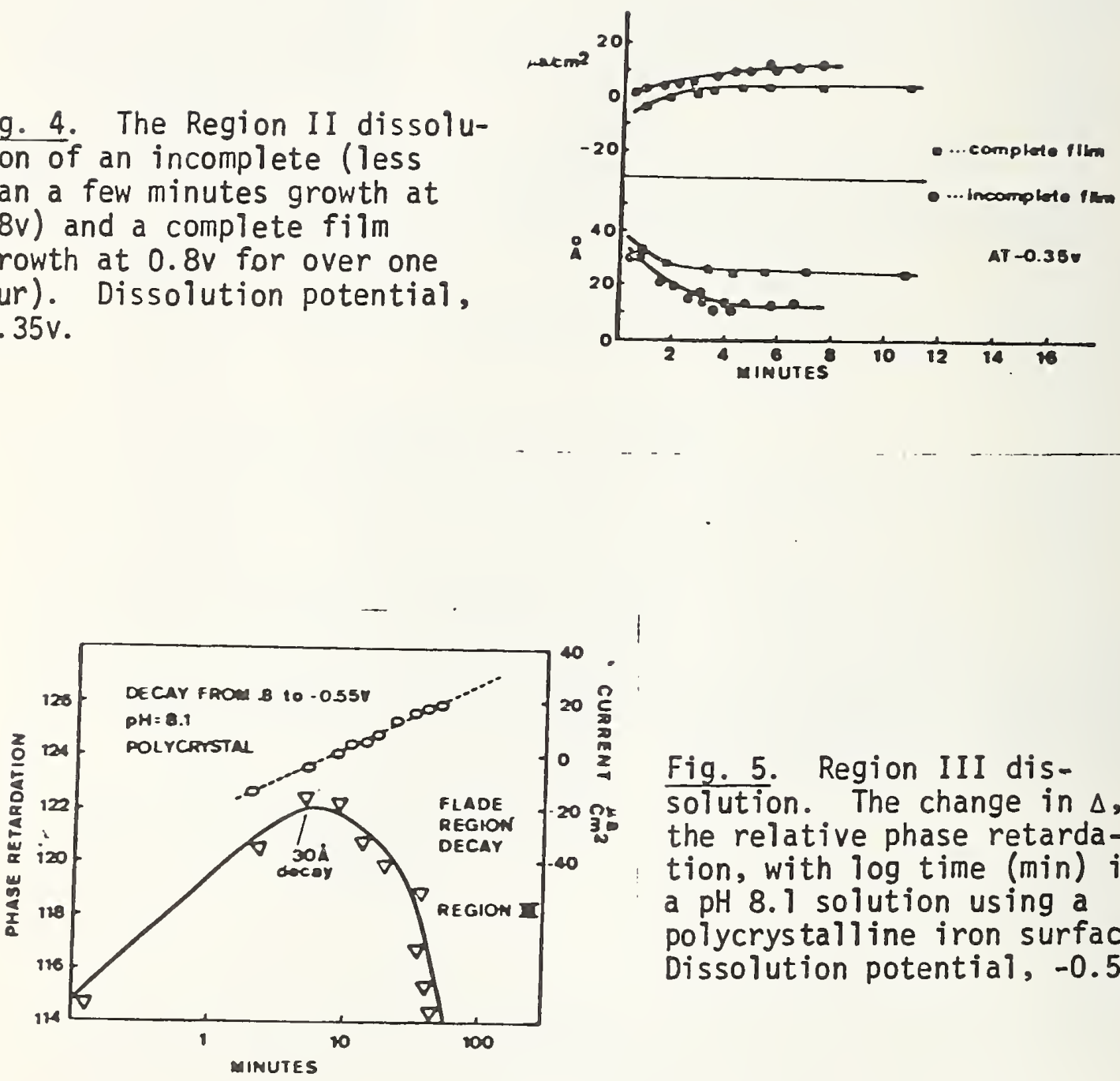

Fig. 5. Region III dissolution. The change in $\Delta$, the relative phase retardation, with log time (min) in a $\mathrm{pH} 8.7$ solution using a polycrystalline iron surface. Dissolution potential, $-0.55 \mathrm{v}$. 


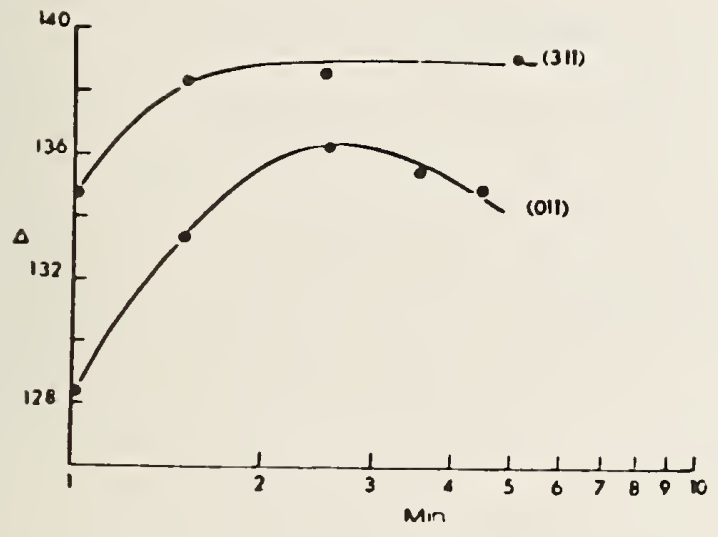

Fig. 6. Region III dissolution. The change in $\Delta$ with log time (min) in a $\mathrm{pH} 8.1$ solution on (311) and (011) iron single crystal surfaces. Dissolution potential, $-0.65 \mathrm{v}$.

Fig. 7. Region IV dissolution. The change in film thickness (A) vs log time (sec) for a $\mathrm{pH} 8.1$ solution. Dissolution potential, $-0.8 \mathrm{v}$.

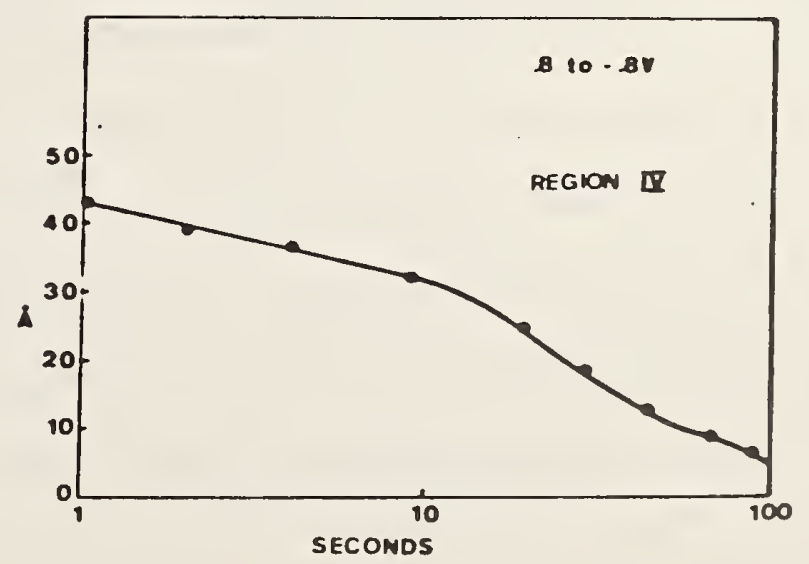


[Part IV - To be submitted for publication in Surface Science.]

FIELD ION MIICROSCOPY OF ALPHA URAHIUII

J. J. Carroll and A. J. Melmed *

Nationa1 Bureau of Standards

Washington, D.C. 20234

\section{$\underline{\text { ABSTRACT }}$}

Field ion micrographs of alpha uranium show atomic details of many orthorhombic crystal planes. Images of the (010) and (007) plane edges are examined and discussed in particular. Micrographs indicate that a surface hydride phase is formed readily under hydrogen imaging conditions. Some micrographs indicate possible hydride particle precipitation at a major crystal defect boundary. No evidence was found, however, of hydrogen/stress induced surface cracks. Procedures used to prepare alpha uranium for field ion microscopy are described.

*Surface Science Division 
Field Ion Microscopy of Alpha Uranium

J. J. Carroll and A. J. Melmed

\section{INTRODUCTION}

Orthorhombic alpha uranium provides a rich source of interesting surface structural characteristics that should be imageable on an atomic scale in the field ion microscopy (FIM). In addition to the orthorhombic lattice dimensions, Fig. $1^{(1)}$ indicates schematically the spatial arrangement of atoms in the $(001),(100)$, and (010) planes. The overall crystal structure is similar to hcp but less symmetric and, therefore, more complicated. The orthorhombic (001) plane is comparable to the hcp (0001) plane. The planar (001) atoms are arranged as a centered rectangle and consecutive layers shift back-and-forth in the $\langle 010\rangle$ directions yielding an $A, B, A, B, \ldots$, stacting seguence. The orthorhombic (1no) plane is comparable to hcp (1150) plane. Consecutive (100) planes are shifted similarly to the (001) planes, resulting in an $A, B, A, B, \ldots$, stacking sequence. Of the three major faces, the orthorhombic (010) plane is most complicated. It is comparable to the hcp (10i0) plane with the atoms lying in a plane having an $A, B, C, D, A, B, C, D, \ldots$, stacking sequence. The (010) plane and all orthorhombic planes of the type $(h, k>0, l)$ are described ${ }^{(2)}$ alternatively as having a corrugated arrangement of atoms lying in a thin selvedge. This description leads to an $A, B, A, B, \ldots$, stacking sequence. Although alternating stacking sequences were observed in FIII studies of hcp metals, ${ }^{(3)}$ no micrographs of crystal planes showing any stacking sequences were observed in FIM studies of alpha uranium. (4-6) lloreover, an indexed helium-hydrogen field ion micrograph of alpha uranium $^{(4)}$ shows a central (010) plane lacking the necessary two-fold 
symetry about two orthogonal axes perpendicular to the <010> direction. Micrograph quality was inadequate in the earlier studies $(4-6)$ for such important features to be observed, thus indicating a need for improved image quality. Studies of uranium using STEM have proceeded to the staje of imaging isolated atoms, and lattice spacings in a crystalline form. (7)

Uranium is known to interact strongly with hydrogen at room temperature and, under certain circumstances, to embrittle. A surface study $^{(8)}$ of the change in work function due to hydrogen chemisorption on uranium thin films prepared in ultra-high vacuum indicates substantial surface hydride formation without significant hydrogen absorption. $\Lambda$ metallographic electron microscope study ${ }^{(9)}$ of uràniium specimęhs charged with hydrogen indicates the primary cause of embrittlement is precipitation of a hydride phase, preferentially but not exclusively at grain boundaries, leading to specimen fracture under stress.

Uranium presents itself through field evaporation in the FIM, usually in a relatively inert imaging gas, as a multifaceted single or polycrystalline surface while undergoing tensile stress. (10) Interacting such a surface with hydrogen gas under imaging conditions can provide, in principle, information regarding the hydrogen-uranium surface interaction, such as the occurrence of hydrojen/stress induced crystal defects. The technique was used successfully in other hydrojen/metal/stress systems. The following includes a description of the preparation of alpha uranium specimens for field ion microscopy, a method of obtaining improved micrographs of alpha uranium in an unbaked microscope, and an FIll view of the hydrogen/alpha uranium/stress interaction. 


\section{EXPERIMENTAL}

An ingot of depleted uranium was swaged at room temperature, with intermediate vacuum annealing treatments at $600 \mathrm{C}$, to about $0.5 \mathrm{~mm}$ diameter wires. Wires were annealed finally in vacuum at $1000 \mathrm{C}$ for several hours and cooled slowly to obtain the alpha phase. (An attempt to electrotransport ${ }^{(12)}$ purify a wire segment was not successful after annealing in $1.3 \times 10^{-5} \mathrm{~Pa}$ vacuum with a (dc) current at $1000 \mathrm{C}$ for twelve days.) Spectrographic analysis of the wire revealed that the uranium was $99.4 \%$ pure with 0.5 wt.\% iron as the major impurity constituent. (13)

The following electropolishing steps were used to make sharp alpha uranium tips suitable for the FIM: (a) the wire diameter was significantly reduced and tapered by electropolishing between 40-20V(ac)

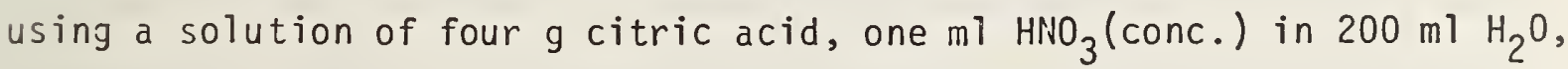
vs. a carbon rod electrode; and, (b) the final polishing step, performed while observing the process at 150 magnification, used the abovementioned electrolyte contained in a loop of $0.13 \mathrm{~mm}$ diameter platinum wire at 20-25 V(ac). Tip shaping and sharpening were controlled with the aid of a micromanipulator that adjusted the position of the platinum loop about the tip-end, and an on/off push-button switch in the.circuit. Specimer:s were rinsed with methanol.

The unbaked field ion microscope was equipped with a $90 \mathrm{~mm}$ diameter microchannel plate and reagent grade imaging gases. A typical cold specimen base pressure of $3.3 \times 10^{-6}$ Pa was obtained in the imaging chamber. The tip temperature was controlled by adjusting the flow of 
cold gaseous helium from a liquid helium reservoir over a specimenmount feed-thru pin. Specimens were cooled to $<30 \mathrm{~K}$.

\section{RESULTS}

3.1. Neon, Helium, and Hydrogen Field Ion Micrographs of Alpha Uranium

Our best micrographs were obtained using neon imaging gas. An example is shown in Fig. 2. Neon field ion micrographs have sufficient overall contrast and yield adequate imageability for most crystal planes. Specimens were stable at neon imaging fields provided that hydrogen and residual gas partial pressures remained low enough. However, neon image quality deteriorated with prolonged imaging or by reimaging, at a later time, a previously field evaporated specimen. In addition to extra bright spots bestrewing the image, as in Fig. 3 (a), patterns developed signs of preferential field attack through the (010) plane and nearly to the (120) and (i20) planes, as in Fig. 3 (b). These image features were removed consistently, as in Fig. $3(c)$, by exposing specimens to Targe enough electric fields in hydrogen to obtain zone line and major crystal plane development as shown in Fig. 4, and then evacuating hydrogen before readmitting neon imaging gas, while maintaining the previously applied voltage. Subsequent neon images remained optimum for $10-20 \mathrm{~s}$ without regard to the amount of field evaporation. In time, extra bright spot development occurred and, with continued field evaporation, preferential etching occurred. This suggests that the extra bright spots originated from a gas-surface interaction rather than from the bulk alpha uranium. 
Alpha uranium images obtained with helium were relatively dim and marginally stable with most crystal planes visible but with less image quality than with neon.

Hydrogen field ion micrographs of alpha uranium (Fig. 4) showed satisfactory overall contrast but most crystal areas were disordered, indicating a significant chemical component of the imaging process between hydrogen and alpha uranium. None of the image enhancement effects were found that typify hydrogen promoted helium or neon images observed with other materials. (10)

\subsection{Crystal Plane Indexing of Alpha Uranium Field Ion Micrographs}

It is known that alpha uranium wire formed by swaging at room temperature develops grains oriented predominantly with their <010> poles aligned parallel to the wire axis, ${ }^{(14)}$ and it was expected that this situation would prevail following the presently used swaging and annealing treatments. Among twenty specimens successfully imaged, thirteen prominently showed the same crystal pole having two twofold axes of symmetry. Thus, the surface plane perpendicular to this pole was identified as the (010) plane. Other crystal planes were indexed with the aid of stereographic projections obtained from several sources. (15) The remaining specimens were divided almost equally between tips centered near the $\langle 001\rangle$ and $\langle 110\rangle$ poles. These results are consistent with results from other studies $(14)$ that showed almost no $<100>$ pole development parallel to the cold swaged wire axis. 


\subsubsection{Image Properties of the (010) Plane Edges}

Neon field ion micrographs of the top-most (010) plane and succeeding (010) plane edges of progressively larger diameter, examples of which are shown in Fig. 5, have important image features that relate to surface structural properties of the field evaporated (010) plane of alpha uranium. The micrographs show a sequential alternation in the relative roughness of succeeding planes and spacings between planes leading to an apparent $A, B, A, B, \ldots$, planar stacking sequence. Designating the more rough looking planes as $A$ and the more snooth looking planes as $B$, the micrographs of Fig. 5 indicate that $A$ planes more closely adjoin the next larger diameter B planes than the previous, next smaller diameter B flanes, judging by the relative ring separations. These image features suggest that the step-height or interplanar spacing is larger between a B plane and the next larger A plane than between an $A$ plane and the next larger B plane, assuming that the local radius of curvature is approximately constant and that conventional field ion imaging theory ${ }^{(16)}$ is applicable.

The foregoing image features may be understood by considering a schematic profile of a field evaporated (010) plane viewed from the $<100>$ direction, as shown in Fig. 6. The corrugated layers are noted by zig-zag lines connecting atom positions in the (010) plane. Atom positions in the plane of the paper are open circled and those close circled are out of the plane of the paper by $\pm 1 / 2$ a spacing. Assuming normal field evaporation, the process exposes alternately the fully corrugated (010) planes and partial (010) planes, where the once 
protruding apex atoms (every other one) were field evaporated. As a result, succeeding step-heights alternate between 0.12 and $0.17 \mathrm{~nm}$; (17) succeeding field evaporated (010) planes alternate between those having more closely packed and more loosely packed atoms. The larger interplanar spacing, shown schematically in Fig. 6, occurs between a B plane and the next largest A plane. This is consistent with the micrographs of Fig. 5 which show a more obvious gap between the more smooth looking planar rings and the next larger, more rough looking planar rings. According to the model shown in Fig. 6, the more rough looking A Dlanar rings of Fig. 5 appear so because atoms are imaged in a corrugated selvedge layer whereas, the more smooth looking B planar rings of Fig. 5 appear so because only atoms of a sinale crystal layer are imaged. Similarly, the $A, B, A, B, \ldots$, stacking sequence observed with FIM is consistent with the $A, B, C, D, A, B, C, D, \ldots$, stacking sequence in the crystal lattice. The FIM A plane images atoms of the A and B crystal layers, the succeeding FI!I B plane images only atoms of the B layer, the succeeding FIII A plane images atoms of the C. and D layers, and the next FIM B plane images only atoms of the ! laver. The $C$ and $D$ crystal layers are indistinguishable from the $A$ and B crystal layers, respectively, since they do not differ in geometry, but differ only in relative lateral positions.

3.2.2. Image Properties of the (001) Plane Edges

Neon field ion micrographs of the (001) plane region are shown in Fig. 7. They indicate that consecutive (001) planes image differently along $\langle 010\rangle$ directions. The edge of the top-most (001) plane is imaged in one $\langle 010\rangle$ direction and environs but fails to image in the 
opposite $\langle 010\rangle$ direction and environs. The edge of the next larger (001) plane images in the directions where the previous (001) plane failed to image. The sequence repeats itself with the result that (001) planes $1,3,5, \ldots$, are imaged in one $\langle 010\rangle$ direction and environs and (001) planes $2,4,6, \ldots$, are imaged in the opposite $\langle 010\rangle$ direction and environs. Consecutive (001) plane edges are imaged in alternate $<010\rangle$ directions and environs leading to an $A, B, A, B, \ldots$, stacking sequence. Consecutive (001) planes, however, are imaged in the $<100>$ directions.

The image features of the (001) plane may be understood with the aid of Fig. 8 which schematically indicates a profile configuration of atoms in field evaporated (001) plane layers viewed from the $\langle 100\rangle$ direction. It is assumed that normal field evaporation prevails and produces single step-height plane layers. The imaging process in field ion microscopy is influenced by the geometrical structure of surface atoms $(18)$ and the availability of surface dangling bonds, favorably or unfavorably disposed for efficient electron tunnelling from the imaging gas. (19) Figure 8 illustrates that the geometries of step-edge atoms and dangling bonds are significantly different in opposite $\langle 010\rangle$ directions on the same (001) plane, and that similar geometries are repeated $i_{i i}$ again opposite $\langle 010\rangle$ directions on consecutive (001) planes. The numbered (.01) planes are lettered with an A and $B$ to emphasize the two different step-edge geometries. If an image of a (001) plane-edge is formed primarily by the availability of surface dangling bonds then, plane-edges $1 B$ and $3 B$ might be imaged in 
one $\langle 010\rangle$ direction and $2 B$ and $4 B$ in the opposite direction. If, however, local radius of curvature at the step-edges primarily influences imageability, then plane-edges $1 \mathrm{~A}$ and $3 \mathrm{~A}$ might be imaged in one $\langle 010\rangle$ direction and $2 \mathrm{~A}$ and $4 \mathrm{~A}$ in the opposite direction. Close inspection of micrographs reveals some evidence that the dim parts of the top-most (001) plane are preferentially field evaporated exposing an unusually large terrace of the second (001) plane layer. See Figs. $7(a)$ and 9. We conclude, therefore, that sten-edge geometry of tine A is exposed to a larger local field due to a smaller radius of curvature and that (001) plane imaging is controlled by imaging gas orbital overlan with dangling bonds at step-edge type $B$.

As the viewing direction is changed from the $\langle 100\rangle$ to the $\langle 010\rangle$ direction, the profile schematic of the (001) plane dramatically changes due to the loss of the corrugated (010) plane layers in the plane perpendicular to the paper. There are equivalent step-edge geometries on consecutive (001) planes in both $\langle 100\rangle$ directions leacina to the imageability of consecutive (001) planes in both $<100\rangle$ directions.

3.3 Field Electron Emission from Alpha Uranium

Fig. 10 shows a field electron emission pattern obtained from an alpha uranium specimen previously imaged and field evaporated with neon. The microscope was not baked, so the imaged surface probably is not free completely from adsorbed residual gas. Nevertheless, these experiments clearly indicate that clean alpha uranium surfaces for field electron emission investigations can be prepared by field 
evaporation at low temperature, at least in neon, and probably in vacuum as well. Moreover, the paitern shown in Fig. 10 is a substantial improvement over a previously published micrograph. (4) Further work must be done to ascertain the stability of the field electron pattern after elevated temperature treatment in ultra-high vacuum.

3.4. Effects Due to Hydrogen

Experiments performed using hydrogen imaging gas indicate that a surface hydride phase is formed readily. For example, prolonged imaging of an as-sharpened alpha uranium tip specimen in hydrogen yièlds micrographs (see Fig. $11(\mathrm{a})$ ) that show significant grain structure. Subsequent micrographs indicate that the grain structured material is removed by neon field evaporation to reveal a single crystalline alpha-uranium substrate. Conversely, micrographs indicate nucleation and growth of surface hydride (see Figs. $11(b, c)$ ) due to exposure of a previously neon field evaporated surface to hydrogen at lower fields, to minimize evaporation. Figs. $11(b, c)$ show the formation and lateral growth of bright centers of emission that we interpret as hydride nuclei. Assessments of hydride formation are derived from qualitative differences amony micrographs within the limitations of conventional field ion microscopy since an atom-probe FIil ${ }^{(20)}$ was not available for these studies.

Neon field ion micrographs of alpha uranium failed to show any significant lattice defects resulting from prior hydrogen surface treatments, as in Fig. 4 , or those that formed surface hydride nuclei, as in Figs. $11(b, c)$. Alpha uranium specimens usualiy show single 
crystal emission patterns. However, one specimen that showed a major twin or grain boundary following exposure to hydrogen imaging conditions, also showed clusters of brighter. emission centers on the boundary. See Fig. 12. These might correspond also to hydride particles, an interpretation consistent with an earlier finding $(21,9)$ that the hydride phase precipitates predominantly at grain boundaries.

\section{SUMMARY}

Significantly improved field ion micrographs from alpha uranium were obtained and major crystal planes were identified. The preparation procedures used to make field ion emitters from alpha uranium were described as well as imaging techniques used to obtain optimum micrographs in ordinary vacuum. The FIll resolved interesting morphological details of the (010) and (001) crystal plane regions. Exposure to, hydrogen most probably produced a surface hydride phase and may have produced hydride precipitates at a defect boundary found in one specimen .

\section{ACKNOILEDGEMENTS}

We recognize the assistance of F. Biancaniello and J. Smit who formed wires from a depleted uranium ingot, and the Office of Naval Research for partial financial support with Contract NAONR-13-69. 


\section{RLFERENCES}

(1) A. N. Holden, Physical lletallurgy of Uranium (Addison-Wesley, Reading, Massachusetts, 1958) p. 27. The present Figure 1 is taken largely from Fig. 3-1.

(2) ibid., p. 87.

(3) For example, A. J. Melmed and R. Klein, "Field-ion microscopy of ruthenium at $77 \mathrm{~K}, " \mathrm{~J}$. Less-Common Metals 10 (1966) 225-228; A. J. ilelmed, "The structure of field evaporated hexagonal closepacked metal surfaces: rhenium and ruthenium," Surface Sci. $\underline{5}$ (1966) 359-379; A. J. Melmed and J. J. Carroll, "Field ion microscopy of osmium," J. Less-Common Metals 30 (1973) 199-204.

(4) A. L. Suvorov, G. i1. Kukavadze, T. L. Razinkova, B. V. Sharov, V. A. Fedorchenko, A. F. Bobkov, and B. Ya. Kuznetsov, "Field ion microscopy of uranium. Preliminary results," Soviet Atomic Energy 36 (1974) 14-18.

(5) A. L. Suvorov and G. M. Kukavadze, "Field ion microscopy of uranium," Problems of Atomic Science and Engineering, Ser.: Physics of Radiation Damages and Radiation Material Science, 1(2), Khar'kov (1975) 72-73.

(6) A. L. Suvorov, G. M. Kukavadze, D. M. Skorov, A. F. Bobkov, B. Ya. Kuznetsov, B. A. Kalin, V. B. Volkov, and S. V. Zaitsev, "Field ion microscopy of uranium in a continuous field evaporation system," Soviet Atomic Energy 38 (1975) 72-77.

(7) M. Isaacson, M. Ohtsuki, and :1. 'Jtlaut, "Electron microscopy of individual atoms," in: Introduction to Analytical Electron Microscopy, Eds. J. J. Hren, J. I. Goldstein, and D. C. Joy (P1enum, New York, 1979) Chapter 13.

(8) J. C. Rivière, "The surface potential of hydrogen on uranium," Nuovo Cimento Suppl. $\underline{5}$ (1967) 466-471.

(9) C. J. Beevers and G. T. Newman, "Hydrogen embrittlement in uranium," J. Nucl. Materials 23 (1967) 10-18.

(10) E. W. Müller and T. T. Tsong, Field Ion Microscopy: Principles and Applications (Elsevier, New York, 1969) pp. 156-169.

(11) J. J. Carrol1, J. Smit and A. J. llelmed, "Field ion imaging of titanium and effects due to hydrogen," Surface Sci. 45 (1976) 640-648, J. J. Carroll and A. J. Melmed, "Field ion microscopy of zirconium," Surface Sci. 58 (1976) 601-604; J. J. Carroll, 
A. J. Melmed and J. Kruger, "Hydrogen interaction with stressed titanium-palladium alloys and stressed vanadium explored with field ion microscopy," in: Passive Films, Surface Structure and Stress Corrosion Susceptibility (NBSIR 80-2101) August, 1930.

(12) D. T. Peterson, F. A. Schmidt, and J. D. Verhoeven, "Electrotransport of carbon, nitrogen and oxygen in thorium," Trans. iletal1. Soc. AIME 236 (1306) 1311-1315; D. T. Peterson and F. A. Schmidt, "Separation of high purity thorium and thorium single crystals," J. Less-Common Metals, 24 (1971) 22?-2?8.

(13) The other impurities identified were $0.003 \mathrm{wt} . \%$ calcium: 0.002 wt. $\%$ silicon, 0.002 wt. \% copper, and 0.005 wt. \% magnesium. The analysis, performed by Herbert 11. Ochs, Denver, Colorado 80223, excluded nonmetallic impurities.

(14) Ref (1), pp. 97-99.

(15) The stereograms of Fig. 5, Ref. (4) were not available to the authors in the beginning of this study. llany stereograms were furnished kindly by Ron Anderson, IBM Corp., Hopewell Junction, N. Y. 12533. Other useful stereograms are found in Ref. (1), pp. 79-83.

(16) Ref. (10), Chapters II, III, and VI.

(17) C. W. Tucker, Jr., "The crystal structures of metallic uranium," Trans. ASM $\underline{42}$ (1950) 762-770.

(18) A. J.W. Moore, "The structure of atomically smooth spherical surfaces," J. Phys. Chem. Solids 23 (1962) 907-912.

(19) Z. Knor and E. W. Müller, "A refined model of the metal surface and its interaction with gases in the field ion microscope," Surface Sci. 10 (1968) 21-31.

(20) Ref. (10), pp. 130-134.

(21) H. R. Gardner and J. W. Riches, "The effect of uranium hydride distribution and recrystallization on the tensile properties of uranium," Trans. ASM $\underline{52}$ (1960) 728-747. 


\section{FIGURE CAPTIONS}

Figure 1. Orthorhombic crystal lattice showing $\langle 010\rangle,\langle 100\rangle$ and $<001>$ directions and the lattice dimensions of alpha uranium. This is not the unit cell as given by Holden.

Figure 2

Figure 3

Figure 4

Figure 5

Figure 6

Figure 7

Figure 8

Figure 9

Figure 10

Figure 11

Figure 12
A neon field ion micrograph obtained from alpha uranium, $23 \mathrm{kV}$.

Neon field ion micrographs obtained from alpha uranium. (a) $26 \mathrm{kV}$; (b) $24 \mathrm{kV}$; (c) $23 \mathrm{kV}$.

A hydrogen field ion micrograph obtained from alpha uranium, $17 \mathrm{kV}$.

Neon field ion micrographs obtained from the (010) plane region of alpha uranium, $20 \mathrm{kV}$.

A schematic profile of a field evaporated (010) plane in the orthorhombic lattice viewed from the $\langle 100\rangle$ direction.

Neon field ion micrographs obtained from the (001) plane of alpha uranium, $20 \mathrm{kV}$.

A schematic profile of a field evaporated (001) plane in the orthorhombic lattice viewed from the $\langle 100\rangle$ direction.

A neon field ion micrograph obtained from the (001) plane of alpha uranium, $24 \mathrm{kV}$.

A field electron emission micrograph, $2 \mathrm{kV}$, obtained from alpha uranium previously fielf evaporated. Pattern indexed from the specimen's field ion micrograph.

(a) A hydrogen field ion micrograph from alpha uranium, $8.6 \mathrm{kV}$, obtained after prolonged imaging of an as-sharpened specimen.

(b) A hydrogen field ion micrograph, $15 \mathrm{kV}$, obtained from alpha uranium previously neon field evaporated and exposed to hydrogen imaging conditions for 15 minutes.

(c) A hydrogen field ion micrograph, $16 \mathrm{kV}$, obtained from alpha uranium previously neon field evaporated and exposed to hydrogen imaging conditions for 30 minutes.

Neon field ion micrographs obtained from alpha uranium, $27 \mathrm{kV}$, with a crystal defect boundary. Two and three clusters of material at the boundary are indicated by circles in (a) and (b), respectively, and are assumed to be uranium hydride particles. Particle dimensions range from 6 to $19 \mathrm{~nm}$. 


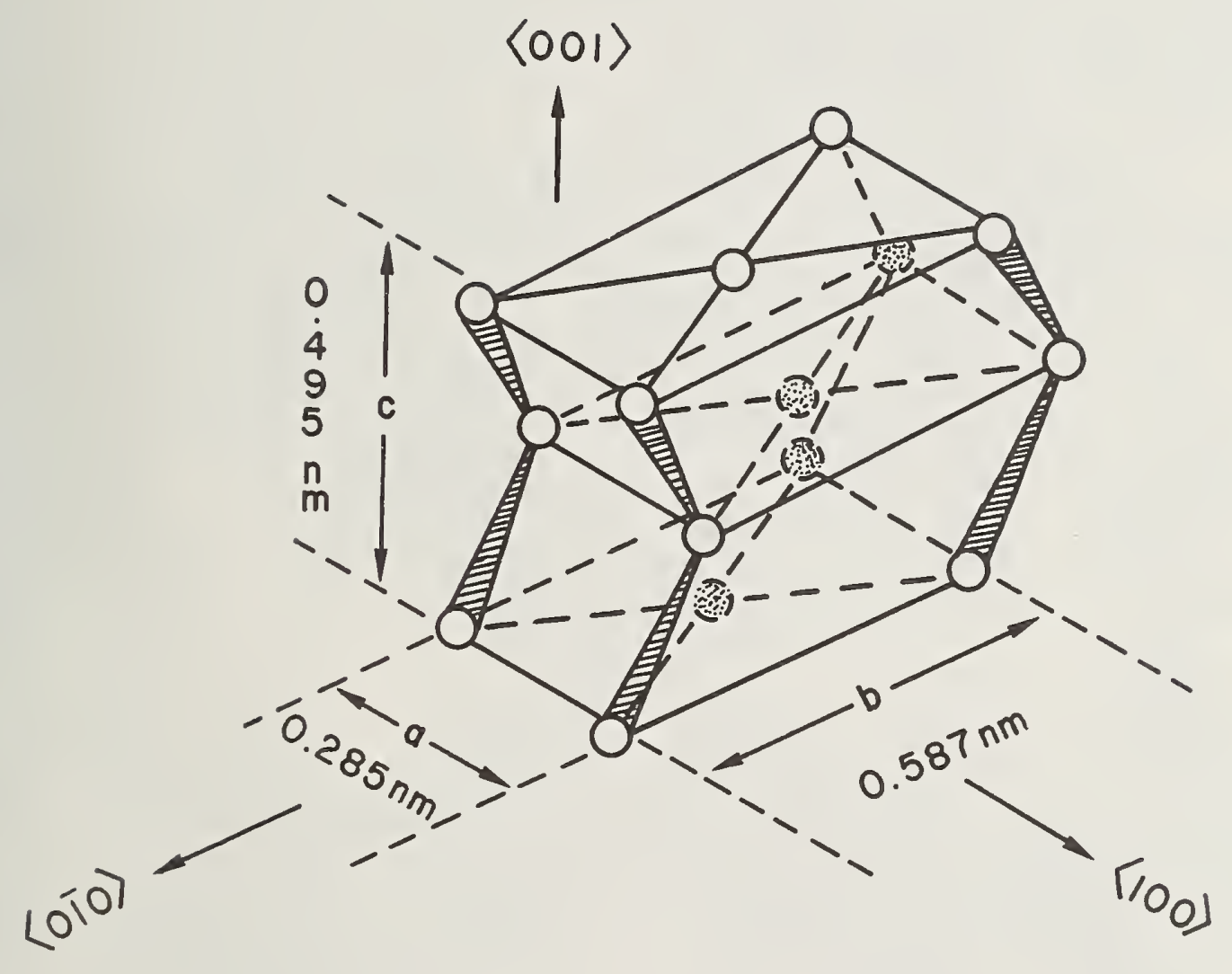




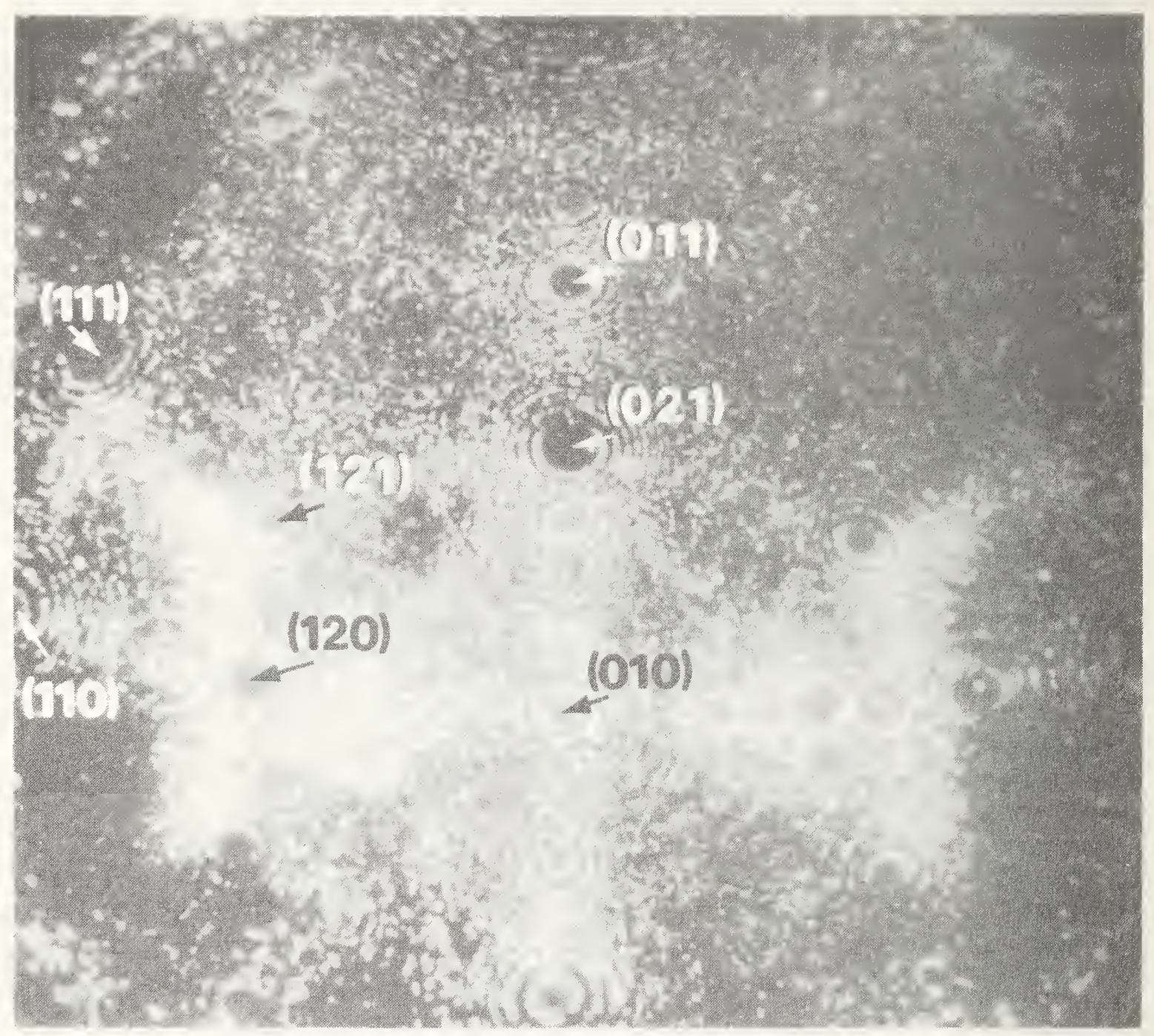

fig 2 

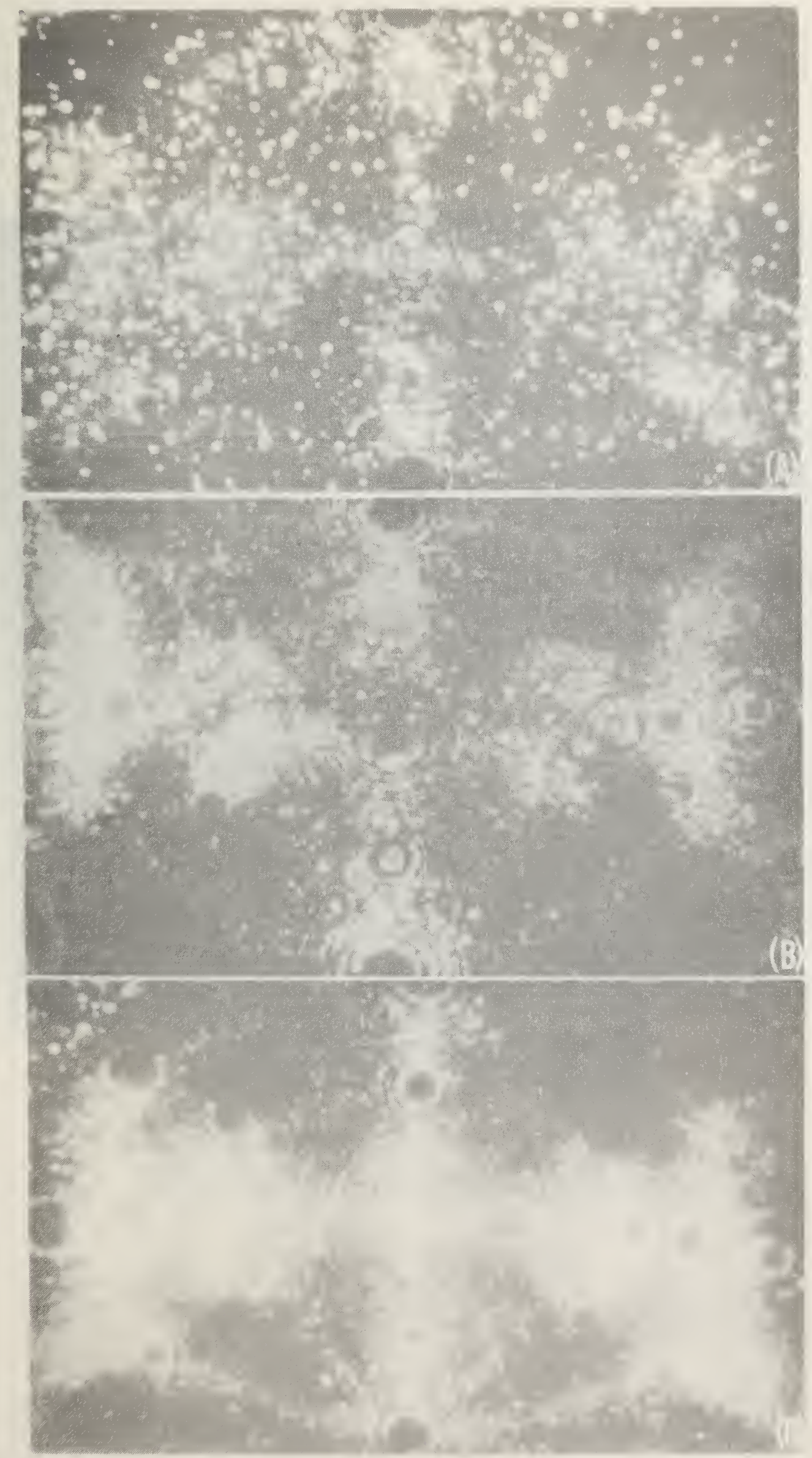


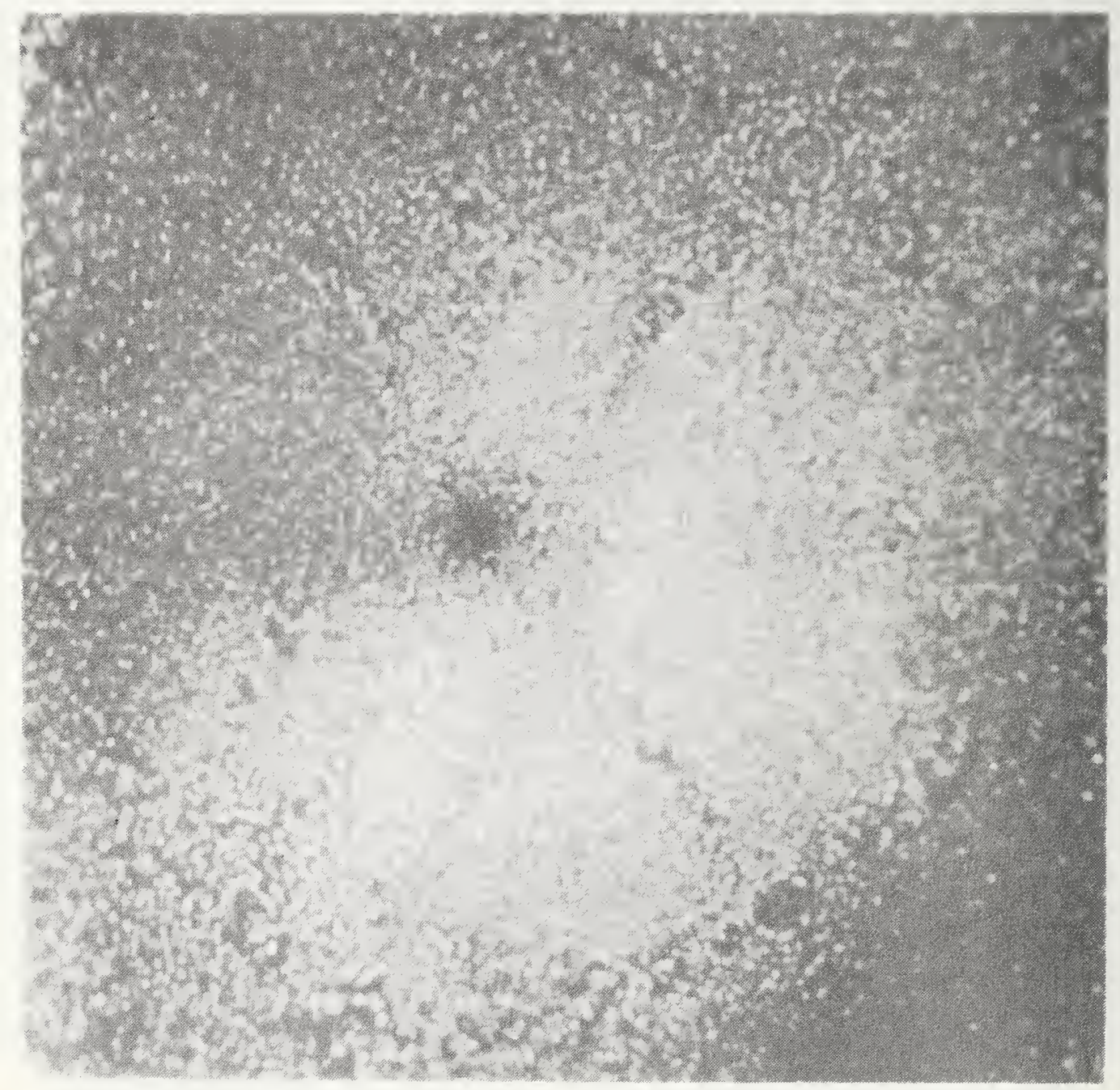




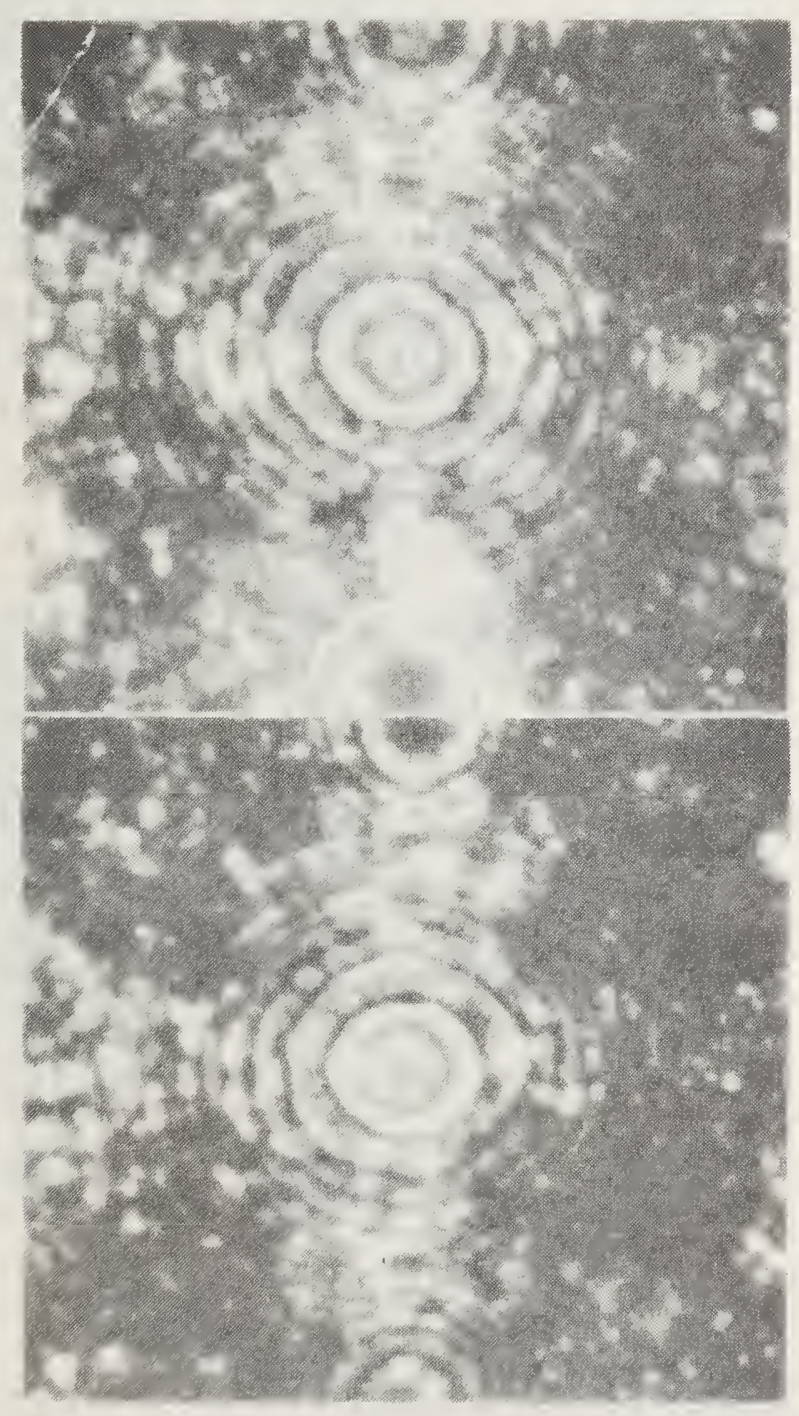

Fys 


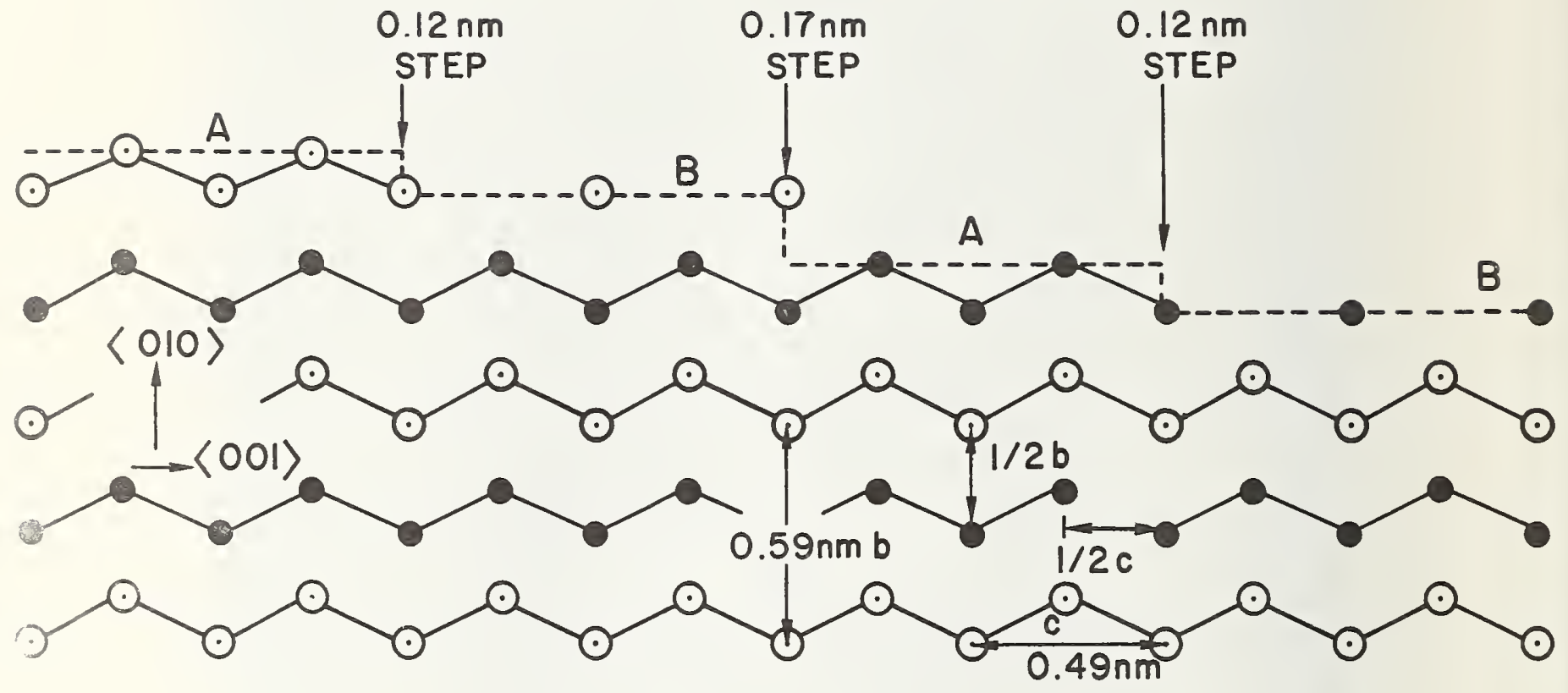

Fig 6 


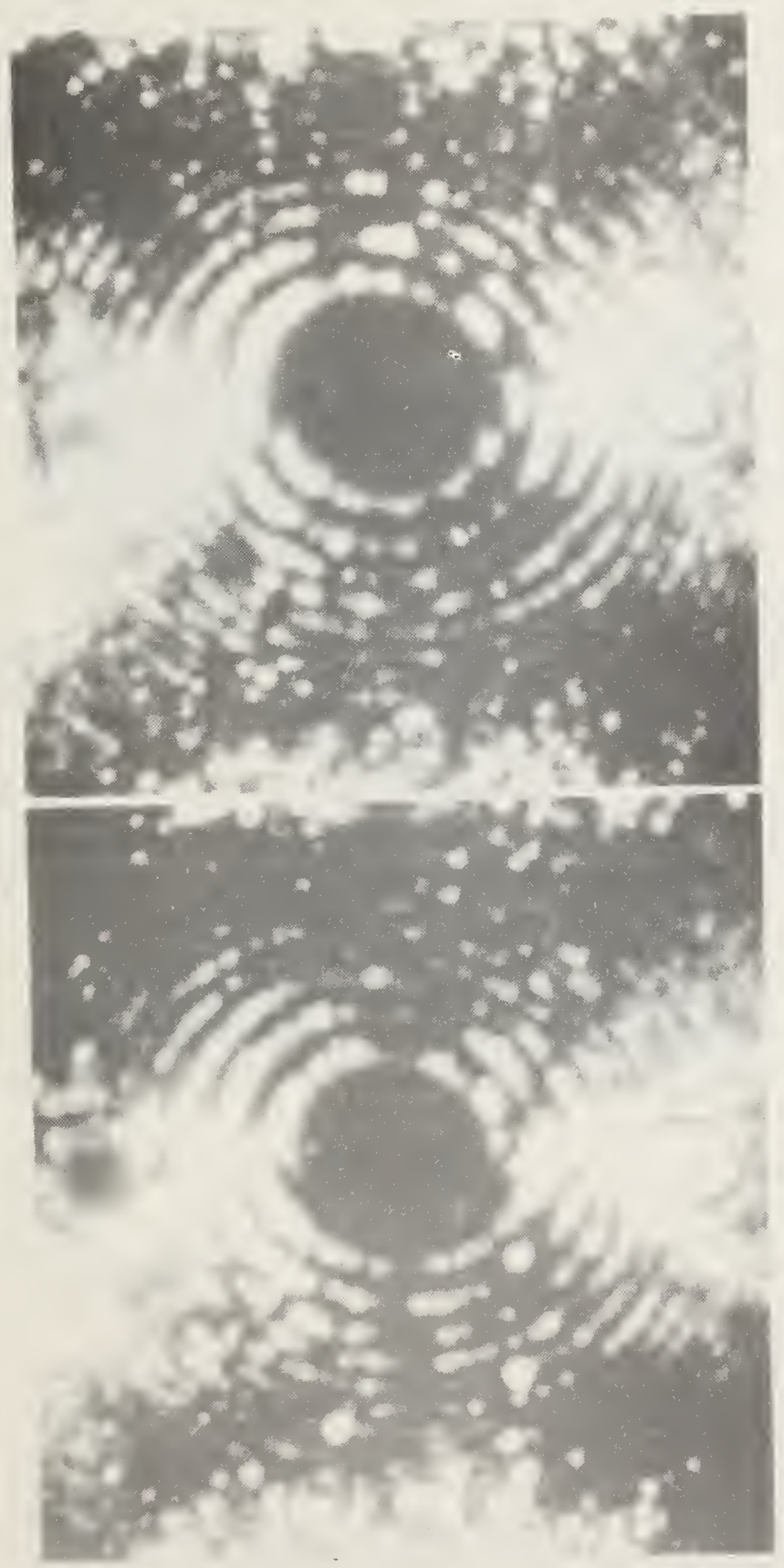

Fig 7 


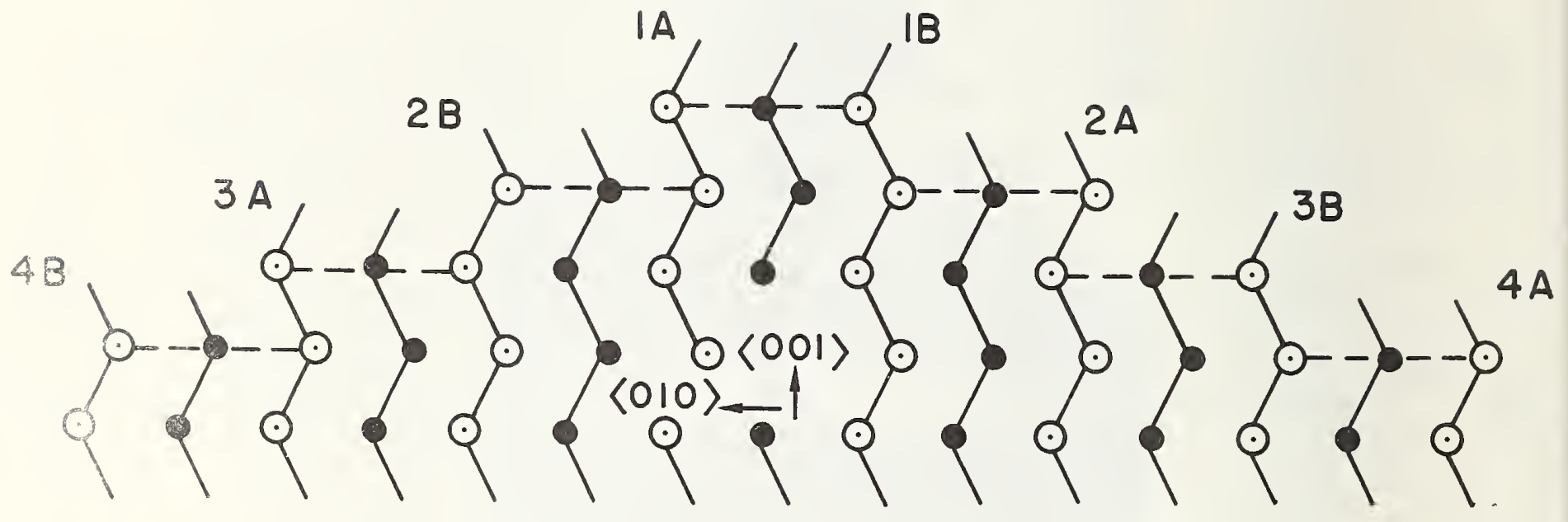

Fig 8 


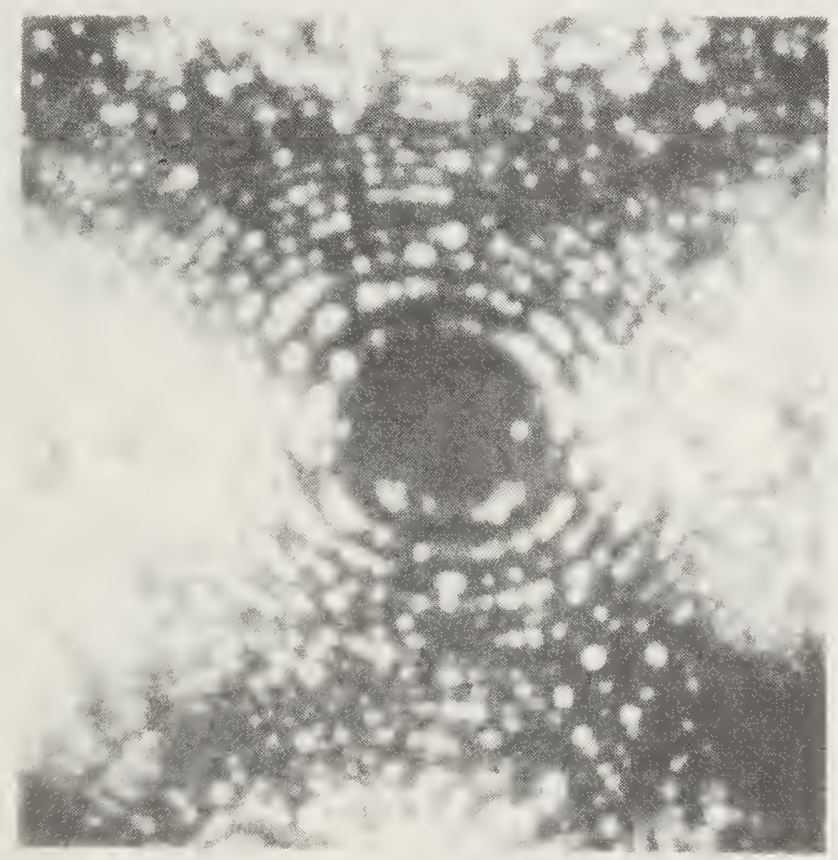

Fig 9 


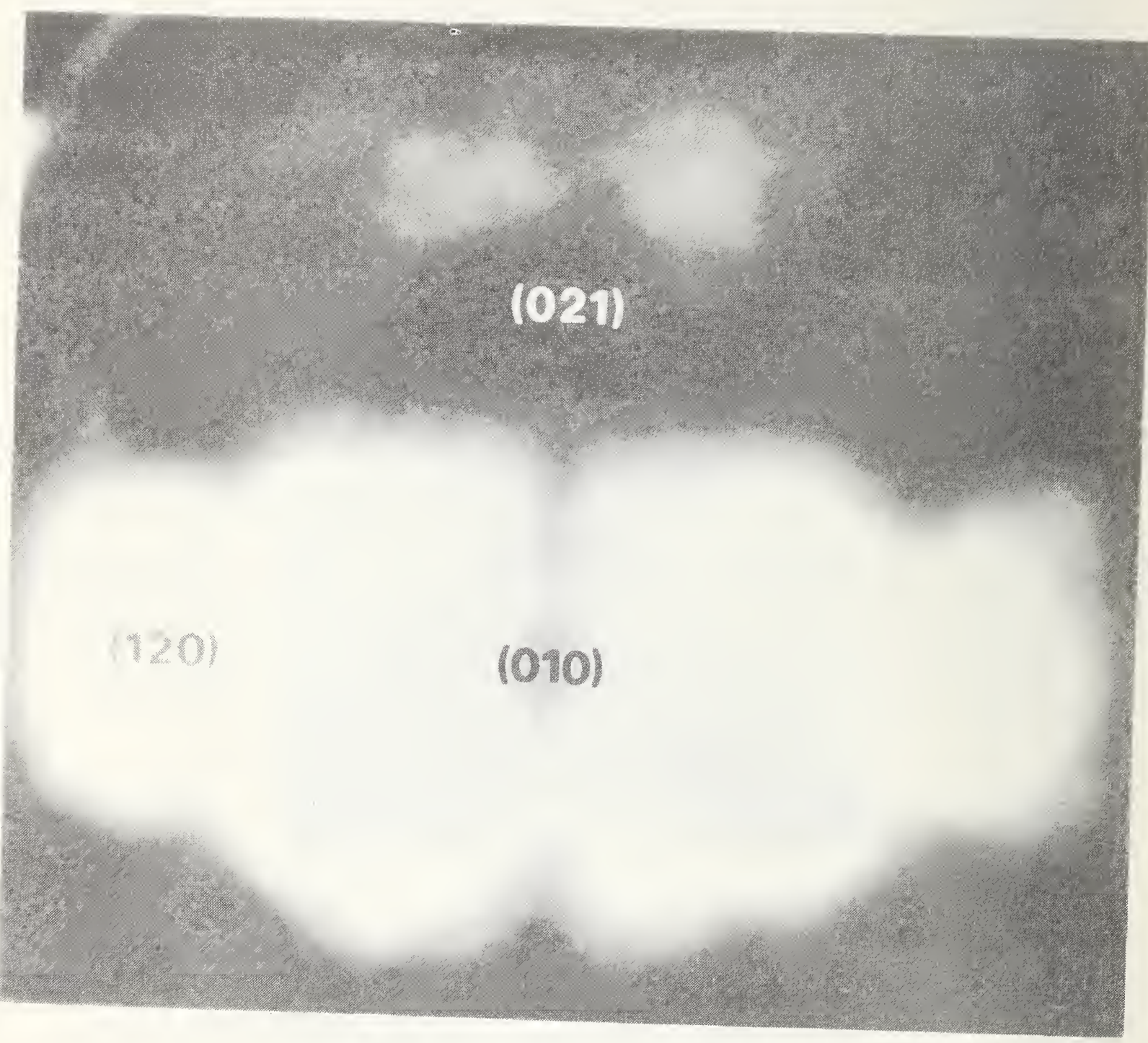

$F_{19} 10$ 

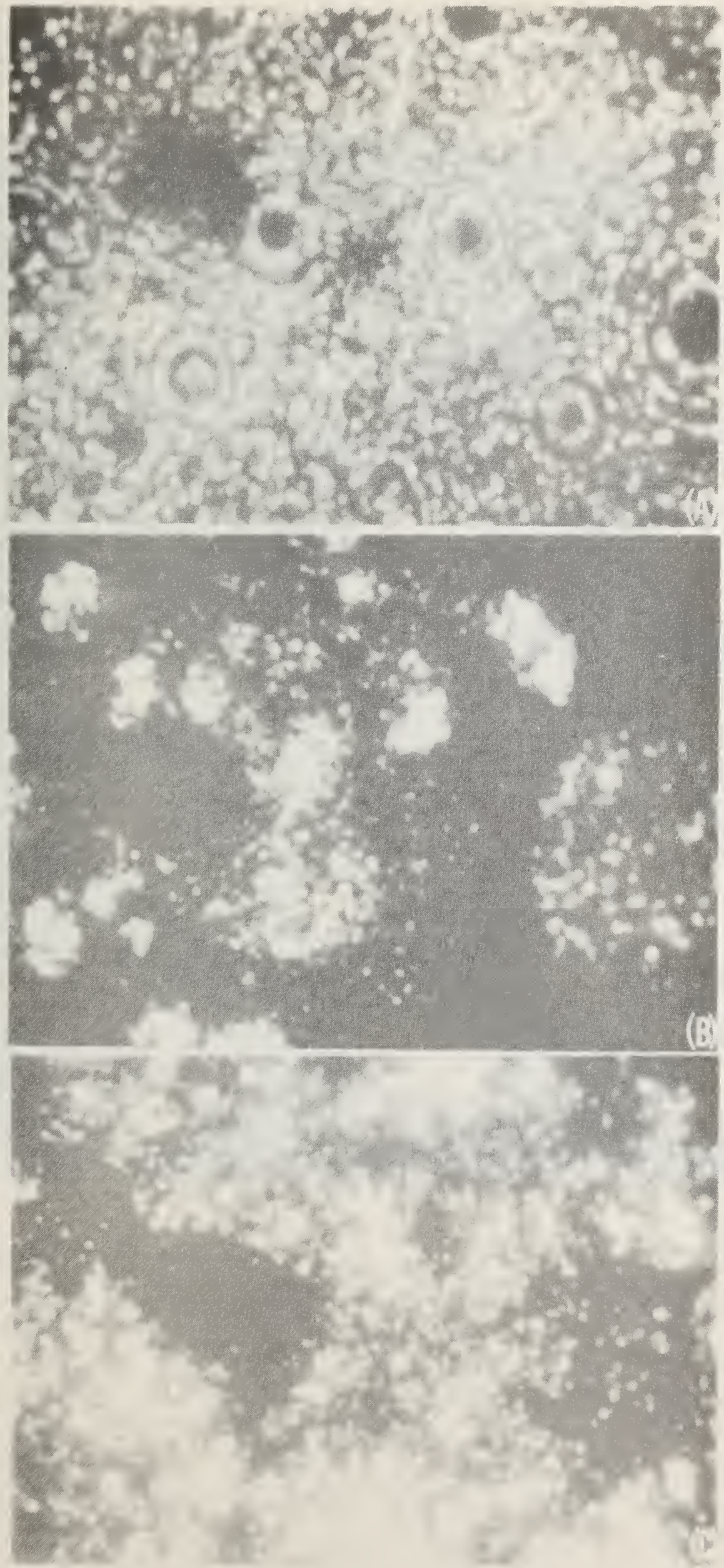

Fig. II 


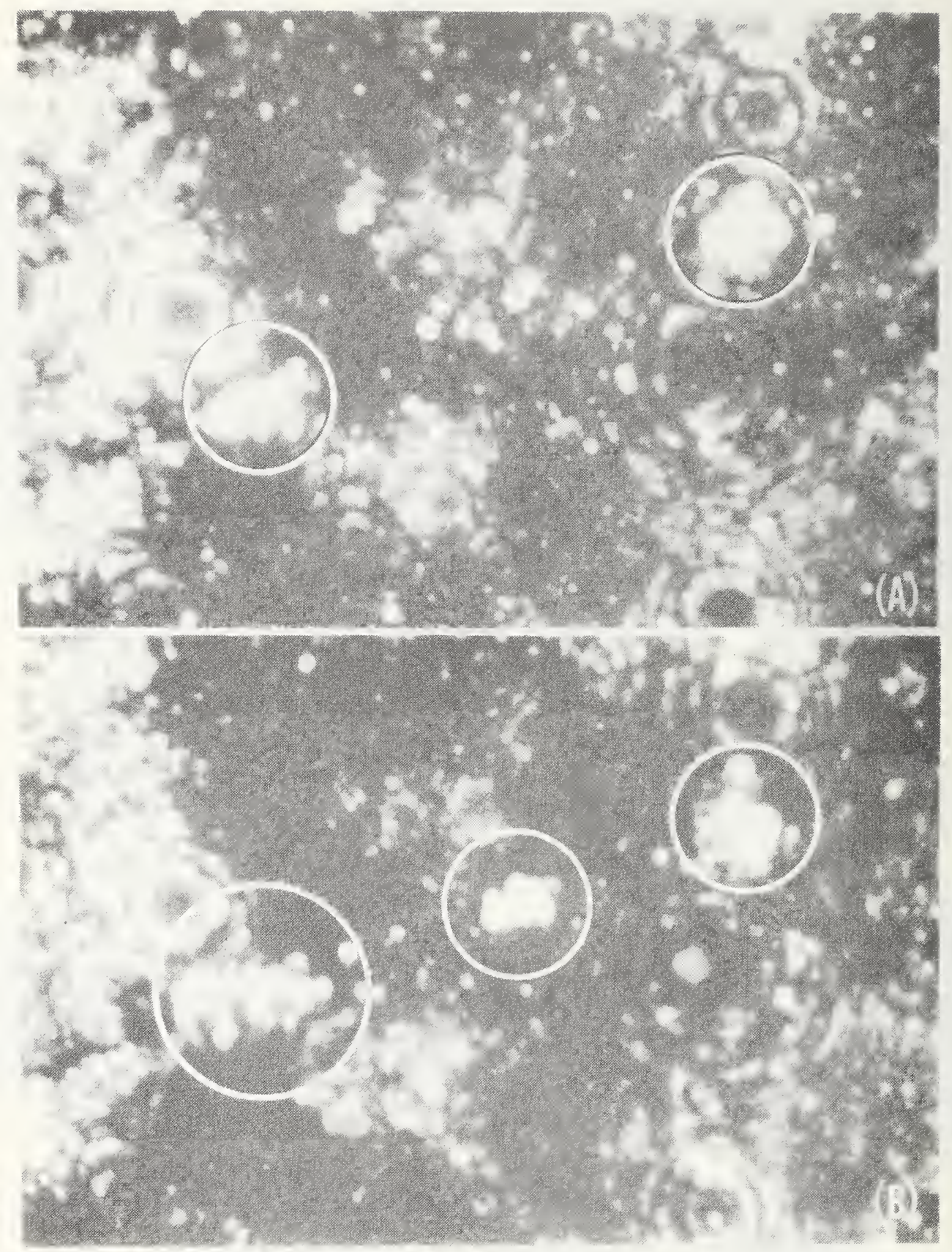


Part V - From Preprints of Svmposium on Advances in Coating Metals for Corrosion Protection, Division of Polvmer Chemistry, American Chemical Societv, Yol. 43, p. 575 (1980).

A New lilipsometric-Electrochemical Approach to

the Study of Corrosion Under Organic Coatings

J. J. Ritter and J. Kruger

National Measurement Laboratory

Center for Materials Science

National Bureau of Standards

Washington, DC 20234

\begin{abstract}
Qualitative ellipsometry was used in conjunction with electrochemical pli and potential measurements as a technique for the study of corrosion processes occurring under organic coatings. The objective of the work was to gain a deeper understanding of the mechanisms governing the corrosion protective actions of paints on metal surfaces. Computer modeling and experiments with collodion coatings on iron substrates indicated that changes in the ellipsometric parameter $\Delta$ could, for the most part, be safely interpreted as thickness alterations in the substrate oxide film and roughening of the substrate. Experiments with the $\mathrm{Fe}-$ collodicn system in dilute chloride solutions exhibited three sequential stages of activity, two of which could be interpreted in terms of corrosion mechanisns using the optical and electrochemical measurements. Chromate ion as a corrosion inhibitor in coatings was also studied using this techinique, and was shown to have significant effects upon the development of the sub-coating processes.
\end{abstract}



$\Lambda$ New Filipsometric-Filectrochemical Approach to

the Study of Corrosion Under Organic Coatings

J. J. Ritter and J. Kruger

National Measurement Laboratory

Center for Materials Science

National Bureau of Standards

Washington, DC 20234

Recently, a description of a feasibility study ${ }^{l}$ was presented to the 4 th International Conference on Ellipsometry that detailed the application of qualitative ellipsometry to the study of metal substrates covered by transparcnt organic coatings. It was shown that such an approach is feasible and that it can provide insight into the corrosion processes that take place under paints. This paper is a somewhat updated version of that presentation and is concerned with the application of ellipsometry to a study of painted surfaces. This new approach is being pursued because there is still a great lack of understanding of the processes that control. the corrosion protection actions of paints. A recent book, Corrosion Control by Coatings ${ }^{2}$, contains many references to unsolved problems in this field. Of special value for addressing this need would be a technique or technicues that could carry out in situ studies of the growth and dissolution of the oxide films and other films that exist on a metal surface covered by a paint and how changes in the composition of the paint affects these films. Also of great value would be a technique that could detect changes in the organic coating that constitutes the paint, changes in the environment that develops under the coating, and finally how such changes lead to the delamination processes that result in detachment of the paint from the oxide covered metal surface.

The approach described in this paper seeks to provide a way to carry out such studies by simulating the painted metal circumstance through the use of a transparent organic coating deposited on a metal surface. Particles of solid chenicals (e.g., chromates) can be placed around the ellipsometer observation region and under the coatings in simulation of corrosion inhibitors found in paint formulations. These dissolve slowly and modify the environment under the organic coating. A pH probe, located under the coating and at the metal surface, allows monitoring of the subcoating environment.

\section{EXPERINENTAL}

The detailed procedures for specimen preparation, ellipsometer data interpretation and computer modeling have been described previously ${ }^{1}$. The work to be described in this paper adds an experimental step to those described previously; namely, at the end of each experiment with a coated specimen, the collodion coatings were stripped with methanol and the exposed specimen surfaces cathodically reduced in deaerated borate buffer solutions ( $p ! 18.5$ ) at $-758 \mathrm{mV}$ S.H.E. Ellipsometric measurements on the reduced surfaces were recorded and an estimate of total oxide film thickness was obtained. The effects of a high pll environment on the coating material were evaluated by ellipsometric studies of collodion-coated gold specimens in saturated NaOH solutions ( $\mathrm{NI} \sim 15)$. The electrochemical potential and ellipsometric behaviors of uncoated iron specimens were stmilarly cvaluated in this high p!l environment.

Obviously, such a system is too complicated to pernit rigorous quantitative ellipsometric determination of film or environmental optical constants or film thicknesses. Instead, the technique enployed in the work described here is the qualitative one described elsewhere ${ }^{3}$. This approacli measures the time dependence of clianges which occur as indicated by significant alterations in the ellipsometric parancters, $\Lambda$ and $\psi$, and correlates 
these changes with concomitant electrochemical measurements. Thus, for example, the rate of change of metal oxide film thickness (assumed proportional to $\Delta$ ) can be monitored. To help interpret the changes of $\Delta$ and $\psi$ observed, and to judge whether the magnitude and direction are realistic and reasonable, model calculations using the Drude equations and reasonable optical parameters were carried out ${ }^{1}$.

\section{RESULTS AND DISCUSSION}

\section{Collodion Coating on Iron}

Figure 1 indicates that on the basis of changes in $\Delta$, the Fe-collodion system proceeds through three distinct stages. During the first $1000 \mathrm{~min}$., $\Delta$ rises gradually, $\psi$ decreases as does $\phi_{\mathrm{Fe}}$. The pll increased during this period due to the reduction of $\mathrm{O}_{2}$ on cathodic regions of the specimen. The next stage covering from 1000 to $6000 \mathrm{~min}$. shows a considerable decline in $\Delta\left(\sim 25^{\circ}\right)$ concomitant with a continued decrease in $\psi, \phi_{\mathrm{Fe}}$. The $\mathrm{pH}$ tends to higher and higher values. It is proposed that the initiation of the second stage corresponds to the presence of active corrosion somewhere on the metal surface. In the third stage, $\Delta$ undergoes a series of reversals, while $\psi$ and $\mathrm{pH}$ increase. By $5400 \mathrm{~min}$. an anodic area was well developed at the upper corner of the specimen, remote from the $\mathrm{pH}$ probe and ellipsometer observation regions.

On the basis of computer modeling, the first stage of the experiment where $\Delta$ increases and $\psi$ decreases is difficult to reconcile with reasonable events thought to occur under the organic coating. One set of conditions which does predict the divergence of $\Delta$ and $\psi$ as observed is the formation of a liquid film conbined with an increase of the liquid film refractive index and a radical decrease in the refractive index for the oxide film. This would suggest a substantive change in either the chemical composition or the molecular and/or atomic arrangement of the existing oxide film. Undoubtedly, $\mathrm{O}_{2}, \mathrm{H}_{2} \mathrm{O}$ and some $\mathrm{Cl}^{-}$penetrate the coating and arrive at the metal surface during this period.

In the second and third stages the behavior of $\Delta$ and $\psi$ is due to a combination of at least three events; (1) a roughening of the metal surface, (2) and growth of metal oxide film*, and (3) possible chemical changes in the coating material due to the high $\mathrm{pH}$ environment.

The high pll sub-coating environment could promote the dissolution of $\mathrm{Fe}$ with the formation of either $\mathrm{HFeO}_{2}^{-}$or $\mathrm{FeO}_{4}^{-2}$ ions depending on the specimen potential. $*$ Since both ions are colored, an optically absorbing liquid film nay be present while metal dissolution results in surface roughness. Fxperiments with uncoated iron in simulated sub-coating environments (high pll) showed that both surface roughening and oxide film growth occurred. Moreover, experiments with collodion coated gold suggested that the fluctuations in $\Delta$ noted in the third stage may be due in part to a deterioration of the coating material after prolonged exposure to a high pll environment.

*I.eidheiser and co-workers have previously reported on the growth of oxide films on cobalt coated with polybutadiene and immersed in 3 percent NaCl. The sub-coating oxide films were detected by Mössbauer spectroscopy".

**The potentials plotted in Figs. 1 and 2 were determined with the reference electrode inmersed in the bulk solution and probably do not represent the true potential of the metal in its sub-coating environment. Potential measurements on uncoated $F e$ in a pll 15 environment suggests that values from -900 to $-150 \mathrm{ml}$ S.H. E. are nore realistic. 
The contribution of these events to the total change in $\Delta$ (cf Fig. 1) is estimated as follows. The amount of oxtde filın accuinulation is typically $6 \mathrm{~nm}$ as determined from cathodic reduction of stripped specimens in borate buffer media. This measurement accounts for 35 to 40 percent of the total measured angular decrease in $\Delta$. From experiments with collodioncoated gold in high p!l environments, it is estimated that an additional 10 to 15 perccnt of the change in $\Delta$ can arise from changes in the coating itself. The remaining 45-55 percent of the change in $\Delta$ is attributed to surface roughening.

For the purpose of comparison, oxide film accumulation and surface roughening was assessed for uncoated iron specimens after prolonged immersion $\left(10^{4} \mathrm{mjn}\right.$ ) in a pIl $15 \mathrm{NaOH}$ solution. Cathodic reduction indicated that $\sim 30$ percent of the total change in $\Delta$ measured in these experiments was due to oxide film growth while the remaining 70 percent was ascribed to surface roughening. Surface roughening was qualitatively demonstrated in these specimens by cycling the specimen potential between -758 and $+442 \mathrm{mV}$ S.ll. E. and measuring the changes in the $\Delta$ parameter. The observed increase in $\Delta$ values as a result of potential cycling is an indication of surface smoothing.

\section{Collodion Coating on Iron with $\mathrm{K}_{2} \mathrm{CrO}_{4}$ Islands}

Figure 2 shows the first stage of the experiment lasts about $1200 \mathrm{~min}$ and indicates that both $\Delta$ and $\psi$ decreases slightly. The change in $\Delta$ is reminiscent of the changes seen for the gold-collodion system and may simply represent the accretion of liquid under the coating ${ }^{1}$. The concomitant decrease in $\psi$ is consistent with this interpretation, but the magnitude of the change is not as readily explained and must wait additional experiments.

The second stage of the process is notably different from that of the previous experiment in that both the rate of change in $\Delta$ and the overall decrease in $\Delta$, are considerably smaller. Thus, it appears that the $\mathrm{CrO}_{4}^{-2}$ greatly inhibits substrate roughening and film growth in this stage. No third stage was observed.

During the expcriment, the $\mathrm{pH}$ rises to about 10, levels off and fina11y fluctuates between 9.3 and 10 . This signifies some attenuation of the corrosion process and is consistent with the expectations for the effect of chromate inhibitor. After $9800 \mathrm{~min}$. immersion, the chromate islands were nearly obliterated, and three separate and very small anodic regions remote from the fil probe and optical region were noted on the surface.

In general, the presence of the chromate "islands" markedly alters both the first and second stages of the sub-coating-processes while eliminating the third stage altogether within the time frame examined.

\section{CONCLUDJNG CONMENTS}

The main objective of this work was to gajn a better understanding of the corrosion processes occurring under organic coatings. The results described in the prior section indicate that an ellipsometric examination of corrosion processes under coatings can provide useful information hitherto not available from previously tried methods of study. It has been shown using this techuique that:

(1) It is possible to identify three different stages occurring during the first $10^{4}$ minutes with the collodion coating system used in this study. Moreover, one can correlate these optically measured stages with time and pll measurements so that the presence of 
active corrosion at the coated metal surface can be determined in situ in a non-destructive manner.

(2) The effects of an inhibitor-ion such as $\mathrm{CrO}_{4}^{-2}$ can be detected and some preliminary insights gained into the inhibition phenomenon, i.e. that both oxide film growth and surface roughening are supressed.

The implications of these findings to the processes which lead to coating failure (e.g. delamination) are currently under investigation.

\section{ACKNOWLEDGEMENTS}

We are most grateful to the Office of Naval Research, which supported this work under Contract NAONR 18-89 NRO 36-082.

\section{REFERENCES}

(1) J. J. Ritter and J. Kruger, Proc. 4th Int. Conf. on Ellipsometry, Surf. Sci. (in press).

(2) Corrosion Control by Coatings, H. Leidheiser, Jr., Ed., Science Press, Princeton (1979).

(3) J. Kruger and J. R. Ambrose, Surf. Sci., 56, 394 (1976).

(4) Henry Leidheiser Jr., A. W. Simmons and Elsie Kellerman, J. Electrochem. Soc. 120, 1516 (1973). 

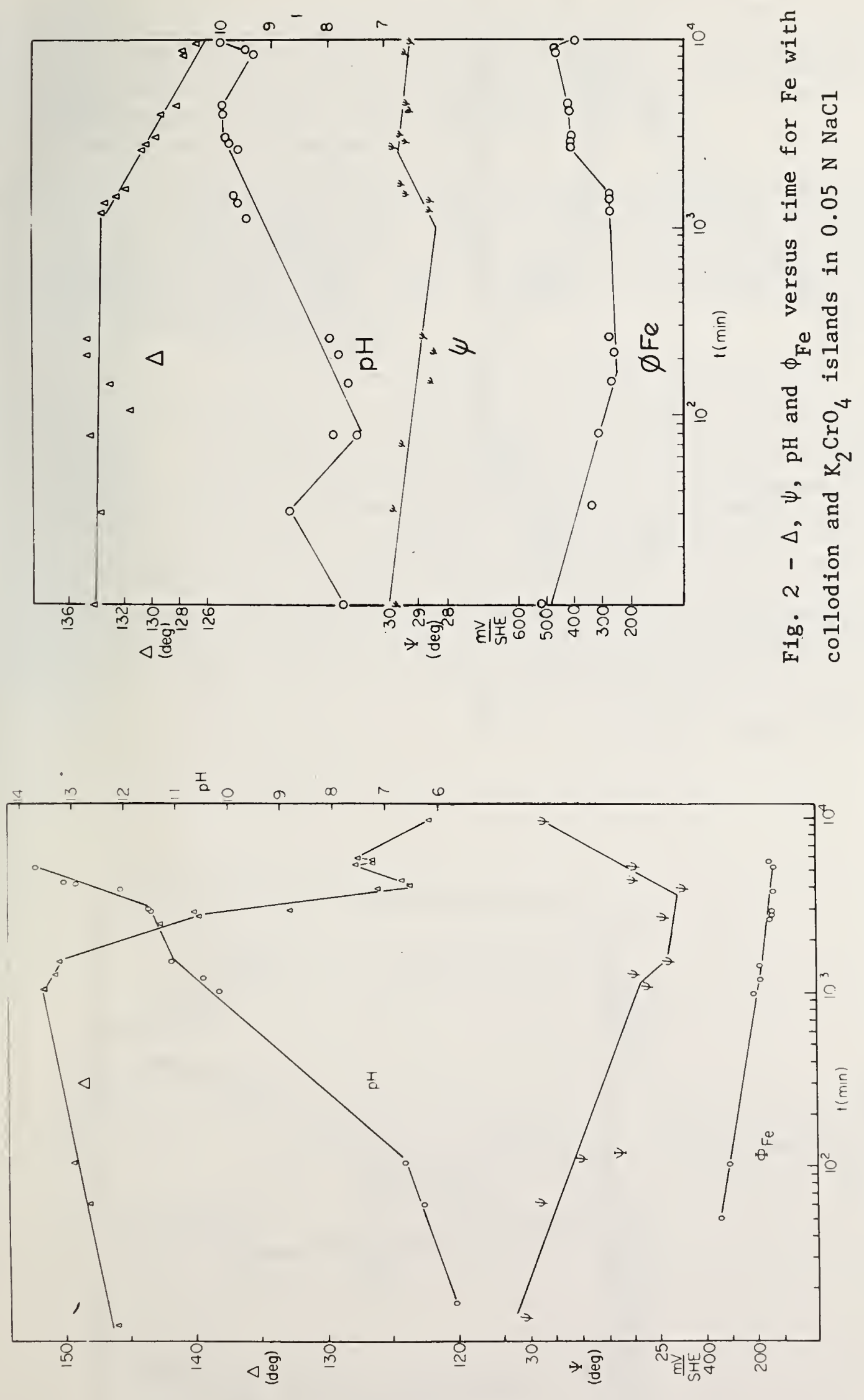

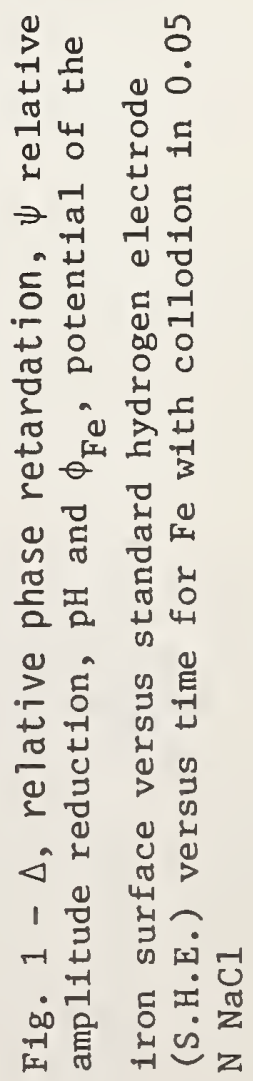




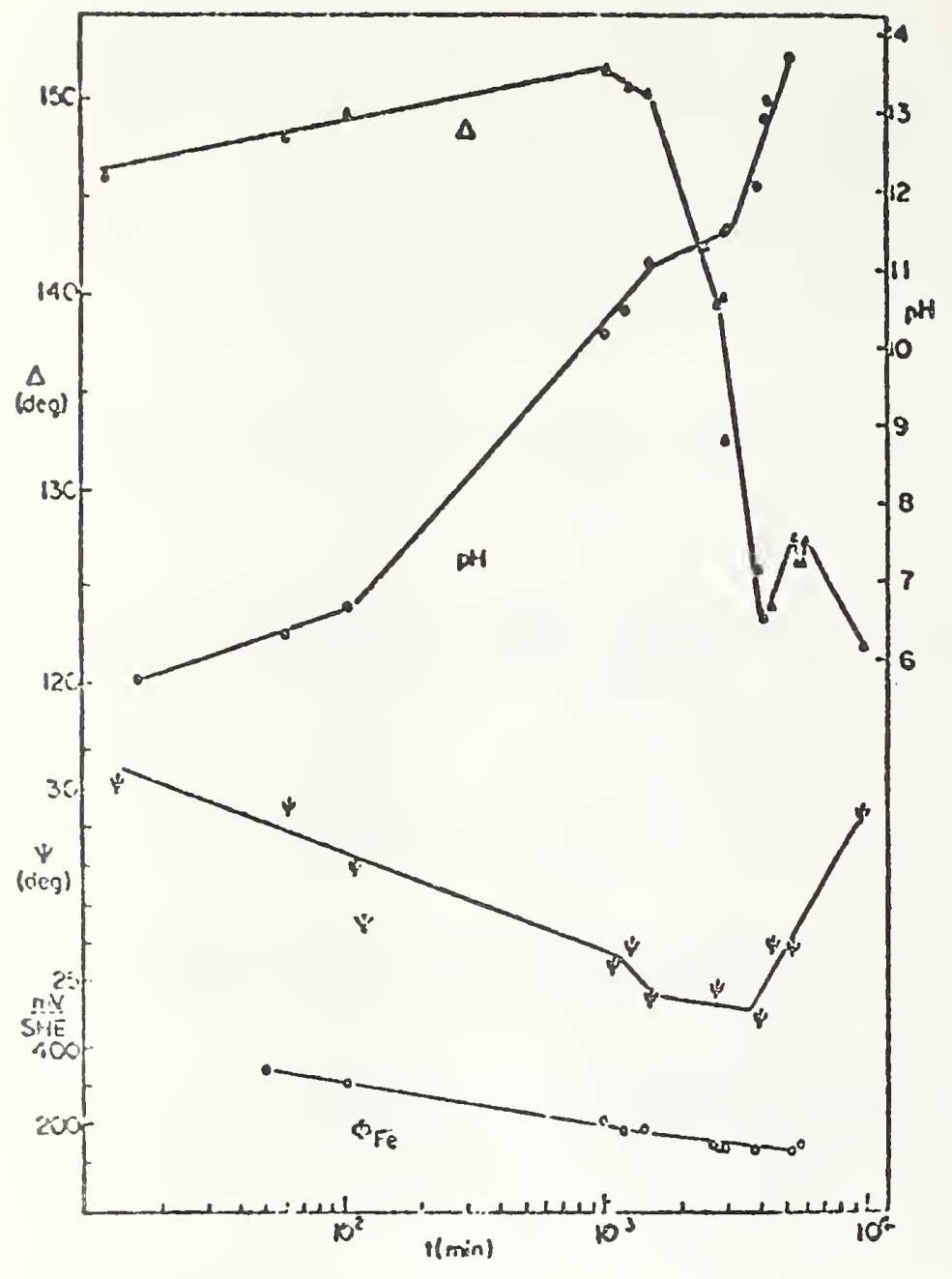

1. $\triangle$, relative phase retardation, $\psi$, relative amplitude reduction, $\mathrm{pH}$ and $\phi_{\mathrm{Fe}}$, potential of the iron surface vs. standard hydrogen electrode (S.H.E.) vs. time for $\mathrm{Fe}$ with collodion in $0.05 \mathrm{~N} \mathrm{NaCl}$.

2. $\Delta, \psi$, pll and $\phi_{\mathrm{Fe}}$ vs. time for Fe with collodion and $\mathrm{K}_{2} \mathrm{CrO}_{4}$ islands in $0.05 \mathrm{~N}$ $\mathrm{NaCl}$.

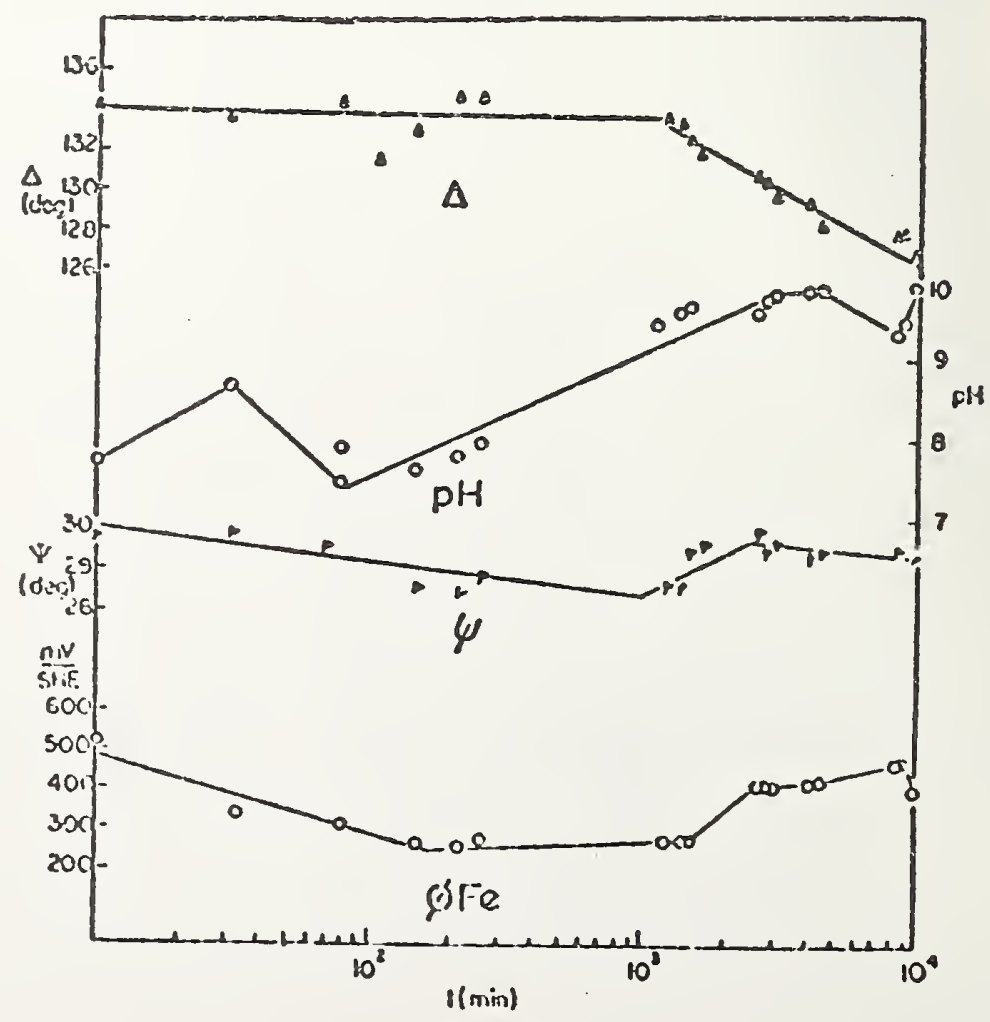


potential regions were identified where different dissolution behavior could be observed. Two different dissolution modes were found at potentials in the passive region; one dissolution mode at potentials at or slightly below the Flade potential, and one mode at potentials where cathodic reduction becomes possible.

Part IV: Field ion micrographs of alpha uranium show atomic details of many orthorhombic crystal planes. Images of the (010) and (001) plane edges are examined and discussed in particular. Micrographs indicate that a surface hydride phase is formed readily under hydrogen imaging conditions. Some micrographs indicate possible hydride particle precipitation at a major crystal defect boundary. No evidence was found, however, of hydrogen/stress induced surface cracks. Procedures used to prepare alpha uranium for fipld ion microscopy are described.

Part V: Qualitative ellipsometry was used in conjunction with electrochemical pH and potential measurements as a technique for the study of corrosion processes cccurring under organic coatings. The objective of the work was to gain a deeper understanding of the mechanisms governing the corrosion protective actions of paints on m: tal surfaces. Computer modeling and experiments with collodion coatings on iron ibstrates indicated that changes in the ellipsometric parameter $\Delta$ could, for the most part, be safely interpreted as thickness alterations in the substrate oxide film and roughening of the substrate. Experiments with the Fe-collodion system in dilute chloride clutions exhibited three sequential stages of activity, two of which could be interpreted in terms of corrosion mechanisms using the optical and electrochemical measurements. Chromate ion as a corrosion inhibitor in coatings was also studied using this technique and was shown to have significant effects upon the development of the subcoating ocesses. 
NBS-11 $4 A$ |REV. 2-8C|

U.S. DEPT. OF COMM.

BIBLIOGRAPHIC DATA

SHEET (See instructions)

4. TITLE AND SUBTITLE
1. PUBLICATION OR REPORT NO.

NBSIR 81-2396 (ONR)
2. Performing Organ. Report Nod

561
3. Publication Date

November 1981

Passive Films, Surface Structure and Stress Corrosion and Crevice Corrosion Susceptibility

5. AUTHOR(S)

J. Kruger, J. J. Ritter, J. J. Carroll, and A. J. Melmed

6. PERFORMING ORGANIZATION (If joint or other than NBS, see instructions)

NATIONAL BUREAU OF STANDARDS

DEPARTMENT OF COMMERCE

WASHINGTON, D.C. 20234

9. SPONSORING ORGANIZATION NAME AND COMPLETE ADORESS (Street, City, STOTE, ZIP)

7. Coneracd Grant No.

NR036-082/1-7-69

8. Type of Report \& Period Covered Annual Report

Aug. 1980 - Aug. 1981

Office of Naval Research

Arlington, VA 22217

10. SUPPLEMENTARY NOTES

[D Document describes a computer program; SF-185, FIPS Software Summary, is attached.

11. ABSTRACT (A 200-word or less foctual summory of most significant information. If document includes a significane tibliography or literature survey, mention it here)

Part I: Transparent organic coatings on iron are used to simulate painted metal surfaces for simultaneous ellipsometric and electrochemical measurements. These studies show that significant changes occur both in the metal oxide film and in the subcoating environment during prolonged immersion in dilute $\mathrm{Cl}^{-}$media. The relationship of these changes to phenomena such as metal passivation, coating delamination, and inhibitor behavior are addressed.

Part II: The corrosion of metals protected by organic coatings is an incompletely understood phenomenon. Recent investigations by an in situ ellipsometricelectrochemical technique combined with microanalytical studies have provided new insights into the destructive processes. Events such as the roughening of the metal surface, chloride ion accumulation and the thickening of the surface oxide have been detected under the coating and are interpreted in terms of the chemistry which develops between the microenvironment and the substrate.

Part III: A description is given of a study of the dissolution of passive films formed by potentiostatic anodic oxidation of iron in sodium borate-boric acid solutions. Using an ellipsometric-potentiostatic techniaue, four different (cont'd.

12. KEY WORDS (Six to twelve entries; alphabetical order; copitolize only proper names; and seporate key words by semicolons)

alpha uranium; chloride ion; chromate ion; electrochemistry; ellipsometry; field ion microscopy; inhibitors; organic coatings; passive film dissolution; pH measurements: surface hydride

13. AVAILABILITY

XX Unlimited

For Official Distribution. Do Not Release to NTIS

O Order From Superintendent of Documents, U.S. Government Printing Office, Washington, D.C. 20402.

14. NO. OF PRINTED PAGES

71

15. Price

XX Order From National Technical Information Service (NTIS), Springfield, VA. 2216I 
